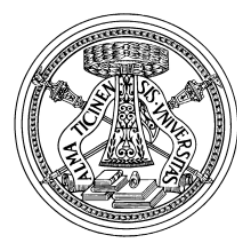

Quaderni di Dipartimento

\title{
Monetary Policy and Automatic Stabilizers: the Role of Progressive Taxation
}

Fabrizio Mattesini

(Università Tor Vergata di Roma)

Lorenza Rossi

(Università di Pavia)

\# 134 (11-10)

Dipartimento di economia politica e metodi quantitativi

Università degli studi di Pavia

Via San Felice, 5

I-27100 Pavia

Novembre 2010 


\title{
Monetary Policy and Automatic Stabilizers: the Role of Progressive Taxation
}

\author{
Fabrizio Mattesini \\ University of Rome "Tor Vergata"
}

\author{
Lorenza Rossi* \\ University of Pavia
}

\begin{abstract}
We study the effects of progressive labor income taxation in an otherwise standard NK model. We show that progressive taxation (i) introduces a trade-off between output and inflation stabilization and affects the slope of the Phillips Curve; (ii) acts as automatic stabilizer changing the responses to technology shocks and demand shocks (iii) alters the prescription for the optimal monetary policy. The welfare gains from commitment decrease as labor income taxes become more progressive. Quantitatively, the model reproduces the observed negative correlation between the volatility of output, hours and inflation and the degree of progressivity of labor income taxation.
\end{abstract}

JEL CODES: E50, E52, E58

\section{Introduction}

In its attempt to provide an increasingly realistic interpretation of the dynamics of actual economies, the New Keynesian literature has not paid much attention to the structure of taxation and, more in general, to the role of

\footnotetext{
*Corresponding author: Department of Economics and Quantitative Methods, University of Pavia, via San Felice al Monastero, 27100 - Pavia (IT). Email: lorenza.rossi@eco.univp.it. phone: +390382986483. We thank Alice Albonico, Guido Ascari, Paolo Bonomolo, Huw Dixon, Rochelle Edge, Andrea Ferrero, Jordi Galì, Henrik Jensen, Anton Nakov and the participants of the "Zeuthen Workshop in Macroeconomics 2010", and of the 2010 EES conference on "Monetary and Fiscal Policy for Macroeconomic Stability" for their comments and suggestions. We also thank the participants of the University of Milan "Bicocca" internal seminar. Lorenza Rossi thanks the Foundation Alma Mater Ticinensis for financial support through the research grant "Promuovere la ricerca d'eccellenza". All errors are our own responsibility.
} 
automatic stabilizers. ${ }^{1}$ This is hardly surprising, given the emphasis of this literature on monetary policy but, as we argue in this paper, the absence of an adequate description of the working of modern tax systems may lead to misleading results and so reduce the empirical performance of the model.

There is evidence, however, that automatic stabilizers, and in particular progressive taxation, significantly affect the response of important time series to the relevant shocks. Auerbach and Feenberg (2000), for example, find empirical evidence that progressive income taxation may help stabilize output both via its effect on the labor supply and via its traditional effect on the aggregate demand. ${ }^{2}$ In a recent paper on the 2007 crisis Dolls et al. (2010) show that automatic stabilizers absorb 38 per cent of a proportional income shock in the EU - with a much larger impact in Northern European countries than in Southern and Eastern European - and 32 per cent in the US. The negative correlation between output volatility and the size of the government sector - a well known stylized fact documented, among others, by Galì (1994) and Fatás and Mihov (2001) - is usually explained with the existence of automatic stabilizers.

In this paper, we concentrate on progressive labor income taxation and we study the macroeconomic consequences of this important automatic stabilizer. As we can see from table 1, almost all governments tax labor income progressively although the degree of progressivity shows huge variability across countries. If we restrict the attention to OECD countries, we go from countries like the Czech Republic where wages are subject to an approximately $20 \%$ tax rate independently of the tax base, to countries like Sweden, where labor income tax rates are $23.4 \%$ for workers earning $67 \%$ of the average wage, more than double for workers that earn $137 \%$ of the average wage and reach $56.4 \%$ for workers earning $167 \%$ of the average wage. Shouldn't we expect significant differences in the dynamics of the Czech and Swedish economies? Shouldn't monetary policy respond differently in a country like Sweden where wage increases above average are so penalized by the tax system than in countries like the Czech Republic where labor income taxes are basically flat?

These questions resemble those concerning the macroeconomic consequences of wage rigidity. While the rigidity of wages however, cannot be

\footnotetext{
${ }^{1}$ To the best of our knowledge, while there is a significant number of studies on distortionary fiscal rules (usually financed by lump sum taxation) such as Schmitt-Grohe and Uribe (2007 and 2010) and Benigno and Woodford (2006), the only NK models that explicitly treat the issue of automatic stabilizers are Andrés and Domenech (2006) and Andrés et al. (2008).

${ }^{2}$ Similarly, Auerbach (2002) finds that automatic stabilizers embedded in the US fiscal system have contributed to cushioning cyclical fluctuations.
} 
taken as given, but must be derived as an equilibrium outcome, the degree of progressivity can be regarded as a structural characteristic of an economy. The aim of progressive taxation is to achieve a more egalitarian distribution of income and therefore is crucially linked to the preferences of society or to the social contract. In analyzing short run stabilization policy, therefore, it can be safely taken as parametric.

In order to introduce progressive taxation in an otherwise standard New Keynesian model, we follow the approach of Guo (1999) and Guo and Lansing (1998) that analyze this issue in a Real Business Cycle framework and suggest a convenient and tractable way to model progressive taxation in representative agents economies.

The consequences of progressive taxation for the New Keynesian model are quite relevant. First, we find that in economies characterized by progressive labor income taxation, policy makers face a trade-off between inflation stabilization and output stabilization. This is quite interesting since it is well known that the New Keynesian model, in its standard version, does not imply any policy trade-offs ${ }^{3}$, while these trade-offs are usually perceived by central banks as a major challenge in formulating monetary policy.

Second, not only we find that in a model with progressive taxation the New Keynesian Phillips curve (NKPC) is significantly affected by productivity and government spending shocks, but we also find that the response of inflation to movements in the output gap increases as the labor income tax becomes more progressive, i.e., the Phillips curve becomes steeper. Economies characterized by a more progressive tax structure, therefore, will typically face a larger trade-off between inflation stabilization and output stabilization. The reason is quite intuitive. Following a productivity shock, output increases, the labor demand schedule shift outwards and real wages must increase. When taxes are progressive, as the real wage increases labor income taxes increase more than proportionally. The supply of labor therefore increases less than in the basic NK model. In order to produce the same amount of output, firms must offer an higher real wage at the cost of setting

\footnotetext{
${ }^{3}$ See for example Galì (2008) ch. 4. In the literature this problem has been dealt with by amending, in some ad hoc way, the NK model. In their "Science of Monetary Policy" Clarida Galì and Gertler (1999) amended the standard NK Phillips curve by adding an exogenous cost-push shock. In a further paper, Clarida Galì and Gertler (2002) proposed a NK model with variable markups. Woodford (2003) discusses a source of monetary policy trade-offs different from cost-push shocks created by the presence of transactions friction. More recently, Blanchard and Galì (2007) have shown that economies characterized by real wage rigidities experience a policy trade-off. While these authors simply assume that the current real wage is a function of the past real wage. Mattesini and Rossi (2009) show that a significant policy trade-off arises also in a two sector economy were one of the two sectors is unionized.
} 
higher prices and therefore higher inflation.

Third, by approximating the model up to a first order, we find that a progressive labor income tax has non-linear dynamic effects and changes the response of the economy to technology, government spending and monetary policy shocks. In particular, progressive labor income taxation acts as an automatic stabilizer: the higher is the degree of progressivity, the lower is the volatility of output and inflation in response to the relevant shocks that hit the economy.

Fourth, studying the dynamic properties of a simple interest rate rule, we find that progressive taxation shrinks the determinacy region: the more progressive is the labor income tax, the smaller is the number of Taylor rules that are able to guarantee a unique rational expectations equilibrium.

Finally, we study optimal monetary policy, both under discretion and under commitment. We follow Benigno and Woodford (2005) who derive a linear-quadratic (LQ) approximation of the households' utility function around a distorted steady state. We find that progressive labor income taxation alters the prescriptions for optimal discretionary monetary policy: a central bank that operates in an economy characterized by a more progressive tax structure should pursue more aggressive monetary policies than a central bank operating in an economy with flatter labor income taxes to push output toward its efficient level. We then study the welfare gains from commitment and we find that they get smaller as labor income taxes become more progressive.

Interestingly, our model not only provides a theoretical framework to study the working of automatic stabilizers, but is also consistent some crucial relationships that are found in the data, such as the negative correlation between output, labor hours and inflation volatility and the degree of progressivity of the tax system.

Theoretical papers that introduce progressive taxation in the New Keynesian model are relatively few. ${ }^{4}$ Heer and Maussner (2006) compare the response of the OLG model to technology and monetary shocks with the corresponding representative-agent model. Vanhala (2006) considers a NK model with matching frictions in the labour market and shows that the effects of an increase in tax progression on macroeconomic volatility cannot be clearly defined and depend on whether taxation is initially progressive or ini-

\footnotetext{
${ }^{4}$ In a paper that is, in some way, related to ours Edge and Rudd (2009) study the effects of nominal taxes on the economy REE equilibrium. They study the effects of a tax on the nominal interest rate, the effect of bracket creep and that of nominal depreciation allowances and show how these tax schemes affect determinacy. Our model focuses on different issues. In particular, we do not consider fiscal drag effects; the marginal income tax increases only when the real wage bill gets higher than its steady state value.
} 
tially proportional. Kleven and Kreiner (2003) analyze the effects of taxation in a menu cost model as in Blanchard Kyotaki (1987) and Ball and Romer (1991) and show that taxes act as automatic destabilizers. Differently from these papers and consistently with the empirical evidence we propose in our empirical exercise, we find instead a clear stabilizing effects of progressive taxation. Furthermore, none of these papers, analyze the consequences of progressive taxation for the inflation-output stabilization trade-off or optimal monetary policy.

The only paper that, to our knowledge, analyzes the welfare consequences of monetary policy with progressive taxation is Collard and Dellas (2005). These authors ask whether and to what extent the existence of variable tax distortions support deviations from perfect price stability and find that optimal monetary policy involves some tolerance of price instability, although optimal departures from perfect price stability are practically small. With respect to this paper, that evaluates numerically the model dynamics, we can characterize analytically the difference between the efficient and the flexible price allocation. This allows us to show analytically how progressive taxation introduces an inflation-output trade-off as well as to provide analytical solutions for the model dynamics and the optimal monetary policy under both a discretionary and a commitment regime. Moreover, while Collard and Dellas (2005) evaluate welfare around an efficient steady state, we study optimal policy in economies that evolve around a distorted steady state as suggested by Benigno and Woodford (2005). ${ }^{5}$

The paper is organized as follows. Section 2 describes the structure of the model. Section 3 studies the model dynamics. Section 4 provides a quantitative evaluation of our model. Section 5 derives analytically the Central Bank welfare function as a linear quadratic approximation of the households' utility function and study the optimal discretionary monetary policy and the welfare gains from commitment as the degree of the progressivity of the labor income taxation varies. Section 6 concludes.

\footnotetext{
${ }^{5}$ Doing so we depart from the widespread practice in the NK literature to evaluate welfare by considering models in which the deterministic steady state is efficient. This last approach introduces a battery of subsidies to production and employment aimed at eliminating the long-run distortions. This is usually done for purely computational reasons. However, as argued by many, this practice has two main shortcomings: (i) the policy instruments necessary to remove the steady state distortions are empirically implausible; (ii) a policy that is optimal for an economy with an efficient steady state will not necessary be so for an economy with a distorted steady state.
} 


\section{The model}

\subsection{Consumer Optimization}

We consider an economy populated by many identical, infinitely lived workerhouseholds, each of measure zero. Households demand a Dixit Stiglitz composite consumption bundle $C_{t}$ produced by a continuum of monopolistically competitive firms. The life-time expected utility function of the representative household is given by:

$$
U_{t}=E_{0} \sum_{t=0}^{\infty} \beta^{\tau-t}\left[\frac{C_{t}^{1-\sigma}}{1-\sigma}-\frac{N_{t}^{1+\phi}}{1+\phi}\right] \quad \sigma, \phi>0
$$

where $0<\beta<1$ is the subjective discount rate, and $N_{t} \in(0,1)$ is the supply of labor hours. Aggregate consumption $C_{t}$ is defined as a Dixit-Stiglitz consumption basket. Labor income is taxed at the rate $\tau_{t}$. The individual flow budget constraint is:

$$
P_{t} C_{t}+R_{t}^{-1} B_{t} \leq\left(1-\tau_{t}\right) W_{t} N_{t}+B_{t-1}+\Pi_{t}(j)-P_{t} T_{t}^{l}
$$

where $P_{t}$ is the price level, $B_{t}$ is the stock of risk-free nominal bonds purchased at the beginning of period $t$ and maturing at the end of the period. $R_{t}$ is the gross nominal interest rate. $W_{t}$ is the nominal wage and $\Pi_{t}$ is the profit income. Households pay a lump sum tax $T_{t}^{l}$ and taxes on labor income $\tau_{t}$. Following Guo (1999) and Guo and Lansing (1998) we postulate that $\tau_{t}$ takes the form:

$$
\tau_{t}=1-\eta\left(\frac{Y_{n}}{Y_{n, t}}\right)^{\phi_{n}}, \quad \eta \in(0,1], \quad \phi_{n} \in[0,1)
$$

where $Y_{n}=W N / P$ represents a base level of income, taken as given by the household. We set this level to the steady state level of per capita income. When the actual income of the household $Y_{n, t}=W_{t} N_{t} / P_{t}$ is above $Y_{n}$ then the tax rate is higher than when the taxable income is below $Y_{n}$. The parameters $\eta$ and $\phi_{n}$ govern the level and the slope of the tax schedule, respectively. When $\phi_{n}>0$ the tax rate increases in the household's taxable income. We impose restrictions on these parameters to ensure that $0 \leq \tau_{t}<1$, and households have an incentive to supply labor to firms.

In order to understand the progressivity of the taxation scheme it is useful to distinguish between the average tax rate which is given by (3), and the marginal tax rate which is given by

$$
\tau_{t}^{m}=\frac{\partial\left(\tau_{t} Y_{n, t}\right)}{\partial Y_{n, t}}=1-\eta\left(1-\phi_{n}\right)\left(\frac{Y_{n}}{Y_{n, t}}\right)^{\phi_{n}} .
$$


Here we consider an environment where $\tau_{t}$ is strictly less than $100 \%$ and where also $\tau_{t}^{m}$ is strictly less than $100 \%$ so that households have an incentive to supply labor to firms. Since $\tau_{t}^{m}=\tau_{t}+\eta \phi_{n}\left(\frac{Y_{n}}{Y_{n, t}}\right)^{\phi_{n}}$ the marginal tax rate is above the average tax rate when $\phi_{n}>0$. In this case the tax schedule is said to be "progressive". When $\phi_{n}=0$, the average and marginal tax rates of labor income are both equal to $1-\eta$, and the labor tax schedule is said to be "flat". 6

Households maximize (1) subject to (2). Therefore, the optimal labor supply and the consumption-saving decision are given by:

$$
\begin{gathered}
C_{t}^{\sigma} N_{t}^{\phi}=\frac{W_{t}}{P_{t}}\left(1-\tau_{t}^{m}\right) \\
1=\beta E_{t}\left[\left(\frac{C_{t+1}}{C_{t}}\right)^{-\sigma} \frac{P_{t}}{P_{t+1}}\right] R_{t}
\end{gathered}
$$

Equation (5) states that the marginal rate of substitution between leisure and consumption equals the real wage net of taxes. Notice, that the presence of $\tau_{t}^{m}$ in equation (5) is due to the fact that households internalize the effects of the marginal tax rate when they choose their supply of labor hours. Equation (6) is the standard Euler equation. Substituting (3) in the households labor supply (5) we get:

$$
C_{t}^{\sigma} N^{\phi}=\eta\left(\frac{Y_{n}}{Y_{n, t}}\right)^{\phi_{n}} \frac{W_{t}}{P_{t}}=\eta Y_{n}^{\phi_{n}}\left(\frac{W_{t}}{P_{t}}\right)^{\left(1-\phi_{n}\right)} N_{t}^{-\phi_{n}}
$$

It is useful to rewrite equations (7) and (6) as log-deviations from their steady state values. In particular, from equation (7) we get:

$$
\sigma \hat{c}_{t}+\phi \hat{n}_{t}=\left(1-\phi_{n}\right) \hat{\omega}_{t}-\phi_{n} \hat{n}_{t}
$$

where $\hat{\omega}_{t}$ is the log-deviation of the real wage. When $\phi_{n}=0$ (the labor income tax is flat) then we get the standard labor supply equation. Equation (8) gives us some important insights on the working of our model. Holding consumption constant, progressive taxation of labor income $\left(\phi_{n}>0\right)$ dampens the response of hours worked to change in real wages. Similarly, holding real wage constant, progressive taxation dampens the response of hours worked

\footnotetext{
${ }^{6}$ As suggested to us by an anonymous referee, the same tax scheme could be generated by a constant proportional tax rate and an allowable deduction. One could therefore talk, more in general, about the sensitivity of the tax rate to income fluctuations, with progressive taxation being a special case of this.
} 
to change in consumption. With an upward sloping tax schedule, therefore, households' incentives to work decrease.

From the log-linearization of the Euler equation (6) we finally get:

$$
\hat{c}_{t}=E_{t}\left\{\hat{c}_{t+1}\right\}-\frac{1}{\sigma}\left(\hat{r}_{t}-E_{t}\left\{\hat{\pi}_{t+1}\right\}\right)
$$

where $\hat{r}_{t}=r_{t}-\sigma \log \beta$ is the log-deviation of the nominal interest rate from its steady state value.

The $\log$ deviation of $\tau_{t}$ in equation (3) from its steady state is given by:

$$
\hat{\tau}_{t}=\frac{\eta \phi_{n}}{\tau} \hat{y}_{n, t}
$$

Since in the steady state $\tau=1-\eta$ and the log-linearization of $Y_{n, t}=W_{t} N_{t} / P_{t}$ yields $\hat{y}_{n, t}=\left(\hat{\omega}_{t}+\hat{n}_{t}\right)$ we can rewrite (10) as:

$$
\hat{\tau}_{t}=\frac{\eta \phi_{n}}{1-\eta}\left(\hat{\omega}_{t}+\hat{n}_{t}\right)
$$

\subsection{The Role of the Government}

The Government always runs a balanced budget. Therefore, in each period the following Government budget constraint holds:

$$
G_{t}=\tau_{t} \frac{W_{t}}{P_{t}} N_{t}+T_{t}^{l}
$$

We assume that public consumption evolves exogenously, so that:

$$
\hat{g}_{t}=\rho_{g} \hat{g}_{t-1}+\varepsilon_{g, t}
$$

where $\hat{g}_{t}=\ln \left(G_{t} / G\right)$ is an exogenous AR(1) process. Exogenous Government spending shocks are useful to study the effects of a temporary changes of the Government size in the economy. A positive Government spending shock temporary increases the Government size. As we will see if the Government spending shocks is followed by a boom in the economy, then output and real wages increase, consequently Government revenues due to progressive taxation must increase, thus acting as automatic stabilizers. ${ }^{7}$

\footnotetext{
${ }^{7}$ Notice that the presence of the lump-sum transfer is needed to balance the Government budget in every period. This assumption does not alter the result on the optimal monetary policy in response to a technology shocks and gives us the advantage to study the effect of an exogenous government spending shock.
} 


\section{$2.3 \quad$ Firms}

\subsubsection{The Final Goods-Producing Sector}

A perfectly competitive final-good-producing firm employes $Y_{t}(u)$ units of each intermediate good $u \in[0,1]$ at the nominal price $P_{t}(u)$ to produce $Y_{t}$ units of the final good, using the following constant return to scale technology:

$$
Y_{t}=\left[\int_{0}^{1} Y_{t}(u)^{\frac{\varepsilon-1}{\varepsilon}} d u\right]^{\frac{\varepsilon}{\varepsilon-1}}
$$

where $Y_{t}(u)$ is the quantity of intermediate good $u$ used as input.

The final good is allocated to consumers and to the Government. Profit maximization yields the following demand for intermediate goods

$$
Y_{t}(u)=\left(\frac{P_{t}(u)}{P_{t}}\right)^{-\varepsilon} Y_{t}
$$

where $Y_{t}(u)=C_{t}(u)+G_{t}(u)$. From the zero profit condition, instead, we have

$$
P_{t}=\left[\int_{0}^{1} P_{t}(u)^{1-\varepsilon}\right]^{\frac{1}{1-\varepsilon}} .
$$

The aggregate resource constraint of the economy is:

$$
Y_{t}=C_{t}+G_{t}
$$

Log-linearizing we get:

$$
\hat{y}_{t}=\gamma_{c} \hat{c}_{t}+\left(1-\gamma_{c}\right) \hat{g}_{t}
$$

where $\gamma_{c}=\frac{C}{Y}$.

\subsubsection{Intermediate Goods Producing Firms}

Intermediate goods producing firms produce a differentiated good with a linear technology represented by the following constant return to scale production function:

$$
Y_{t}(u)=A_{t} N_{t}(u)
$$

where $u \in(0,1)$ is a firm specific index. $A_{t}$ is a technology shock and $a_{t}=\ln \left(A_{t} / a\right)$ follows an $\mathrm{AR}(1)$ process, i.e.,

$$
a_{t}=\rho_{a} a_{t-1}+\varepsilon_{t}^{a}
$$

where $\rho_{a}<1$ and $\varepsilon_{t}^{a}$ is a normally distributed serially uncorrelated innovation with zero mean and standard deviation $\sigma_{a}$. 
Given the constant return to scale technology and the aggregate nature of shocks, real marginal costs are the same across the intermediate good producing firms. Solving the cost-minimization problem of the representative firm and imposing the symmetric equilibrium we obtain the following aggregate demand for labor:

$$
\frac{W_{t}}{P_{t}}=M C_{t} A_{t}
$$

It is useful to rewrite equation (21) in log-deviations:

$$
\widehat{m c}_{t}=\hat{\omega}_{t}-a_{t}
$$

The aggregate production in log-deviations is instead:

$$
\hat{y}_{t}=a_{t}+\hat{n}_{t}
$$

\subsubsection{Staggered Price Setting}

Firms choose $P_{t}(u)$ in a staggered price setting à la Calvo (1983). Solving the Calvo problem and log-linearizing, we find a typical forward-looking Phillips curve:

$$
\hat{\pi}_{t}=\beta E_{t} \hat{\pi}_{t+1}+\lambda \widehat{m c_{t}}
$$

where $\lambda=\frac{(1-\varphi)(1-\beta \varphi)}{\varphi}$ and $\varphi$ is the probability that prices are reset.

\subsubsection{Real Marginal Costs and the flexible price equilibrium out- put}

We now want to find an expression for the aggregate real marginal costs and, after imposing that prices are flexible, derive the flexible price equilibrium output. Given the flexible price equilibrium output (or natural output) we will then derive the output gap, which is defined as the difference between the actual and the flexible price equilibrium output. Let us first consider equilibrium in the labor market which is obtained equating the aggregate demand for labor (21) and the aggregate labor supply (8). This allows us to find the equation for the aggregate real marginal costs, that in log-deviations is given by:

$$
\widehat{m c}_{t}=\frac{\left(\phi+\phi_{n}\right)}{\left(1-\phi_{n}\right)} \hat{n}_{t}+\frac{\sigma}{1-\phi_{n}} \hat{c}_{t}-a_{t} .
$$

Using equations (18), (8) and (23) we can rewrite equation (25) as:

$$
\widehat{m c}_{t}=\frac{\gamma_{c}\left(\phi+\phi_{n}\right)+\sigma}{\gamma_{c}\left(1-\phi_{n}\right)} \hat{y}_{t}-\frac{(1+\phi)}{\left(1-\phi_{n}\right)} a_{t}-\frac{\sigma\left(1-\gamma_{c}\right)}{\gamma_{c}\left(1-\phi_{n}\right)} \hat{g}_{t} .
$$


We know that under the flexible price equilibrium the log of real marginal costs equals the $\log$ of its steady state value, i.e. $m c_{t}=\log \left(\frac{\varepsilon-1}{\varepsilon}\right)$, then $\widehat{m c}_{t}=0$. Therefore, imposing this last condition (which holds only when prices are flexible) and solving for $\hat{y}_{t}$, we find the flexible price equilibrium output which is given by:

$$
\hat{y}_{t}^{f}=\frac{\gamma_{c}(1+\phi)}{\left(\phi+\phi_{n}\right) \gamma_{c}+\sigma} a_{t}+\frac{\sigma\left(1-\gamma_{c}\right)}{\left(\phi+\phi_{n}\right) \gamma_{c}+\sigma} \hat{g}_{t}
$$

As we said before, when $\phi_{n}=0$, the average and marginal tax rates of labor income are both equal to $1-\eta$, and therefore the labor income tax becomes a flat tax. In this case, the flexible price equilibrium output is:

$$
\hat{y}_{t}^{f, f l a t}=\frac{(1+\phi) \gamma_{c}}{\sigma+\phi \gamma_{c}} a_{t}+\frac{\sigma\left(1-\gamma_{c}\right)}{\sigma+\phi \gamma_{c}} \hat{g}_{t}
$$

Note that the difference between (27) and (28) is:

$\hat{y}_{t}^{f}-\hat{y}_{t}^{f, \text { flat }}=-\frac{(1+\phi) \phi_{n} \gamma_{c}^{2}}{\left(\left(\phi+\phi_{n}\right) \gamma_{c}+\sigma\right)\left(\sigma+\phi \gamma_{c}\right)} a_{t}-\frac{\sigma\left(1-\gamma_{c}\right) \phi_{n} \gamma_{c}}{\left(\left(\phi+\phi_{n}\right) \gamma_{c}+\sigma\right)\left(\sigma+\phi \gamma_{c}\right)} \hat{g}_{t}$

In an economy characterized by progressive taxation of labor income, the flexible price equilibrium output is always lower than the one that would arise in an economy where the labor income tax is flat.

\subsection{The Phillips Curve}

Notice that from (26) and (27) we are able to rewrite real marginal costs in terms of output gap, which is defined as the difference between the actual and the flexible price equilibrium output, $y_{t}-y_{t}^{f}$ :

$$
\widehat{m c_{t}}=\frac{\sigma+\gamma_{c}\left(\phi+\phi_{n}\right)}{\gamma_{c}\left(1-\phi_{n}\right)}\left(\hat{y}_{t}-\hat{y}_{t}^{f}\right) \text {. }
$$

Using (30) the NKPC can be written as

$$
\pi_{t}=\beta E_{t} \pi_{t+1}+\lambda \varsigma_{x}\left(\hat{y}_{t}-\hat{y}_{t}^{f}\right)
$$

where $\varsigma_{x}=\frac{\sigma+\gamma_{c}\left(\phi+\phi_{n}\right)}{\gamma_{c}\left(1-\phi_{n}\right)}$. We following Benigno and Woodford (2005) to rewrite the NKPC in terms of the welfare relevant output as,

$$
\pi_{t}=\beta E_{t} \pi_{t+1}+\kappa \hat{x}_{t}+\kappa u_{t}
$$


where $\kappa=\lambda \varsigma_{x}, u_{t}=\left(\hat{y}_{t}^{*}-\hat{y}_{t}^{n}\right)$ and $\hat{x}_{t}=\left(\hat{y}_{t}-\hat{y}_{t}^{*}\right)$ is the welfare relevant output gap.

In Appendix (A1) we show that $u_{t}$ is completely exogenous and, indeed, it is a function of technology and government spending shocks. Therefore, unlike what happens in the standard NK model, the difference between welfare relevant output ${ }^{8}$ and flexible price equilibrium output is not constant, but is a function of the relevant shocks that hit the economy. What Blanchard and Galì (2007) define as the "divine coincidence"9 does not hold since a policy that brings the economy to its natural level is not necessarily optimal.

We are therefore able to state the following:

Proposition 1 Endogenous trade-off. With progressive taxation on labor income an endogenous trade-off between stabilizing inflation and the output gap emerges. The New Keynesian Phillips Curve is affected by technology and government spending shocks.

The endogenous trade-off between inflation stabilization and output stabilization is a consequence of the progressivity of the tax rate. Suppose a positive productivity shock hits the economy. Efficient output and natural output both increase, but natural output increases less. This implies that the welfare relevant output increases more than natural output. The reason is the following. Because of the productivity shock the demand for labor increases and the real wage increases in order to restore equilibrium in the labor market. If taxes were flat, efficient and flexible price equilibrium output would be identical but for a constant, which disappears when we write the two outputs in log-deviation from the steady state. When taxes are progressive, instead, as the real wage increases, labor income tax increases more than proportionally. The supply of labor therefore increases less than in the efficient economy and the increase in the natural output is smaller. Since natural output increases less than the welfare relevant output following a productivity shock, to reduce the welfare relevant output gap the central bank must accept a higher rate of inflation.

It is important to notice that, in this model, the endogenous trade-off between inflation stabilization and output stabilization arises without any assumption on real wage rigidity as in Blanchard-Galì (2007), or on the

\footnotetext{
${ }^{8}$ As shown by Benigno and Woodford (2005) and Gnocchi (2009) among others, when the model economy is log-linearized around a distorted steady state, the welfare relevant output is a function of the efficient and of the natural output.

${ }^{9}$ Blanchard and Galì (2007) define the divine coincidence as the absence, in the standard NK model, of an endogenous trade-off between stabilizing inflation and unemployment.
} 
structure of labor contracts as in Mattesini and Rossi (2009). Rather, it is a simple consequence of the structure of taxation that, in most countries, shows some degree of progressivity. Notice also that the effect of progressive taxation is the opposite of the effect of real wage rigidity. When real wages are rigid, following a productivity shock, natural output tends to increase more than the welfare relevant output, while in the case of progressive taxation natural output tends to increase less than the welfare relevant output. Progressive labor income taxation, therefore, acts as an automatic stabilizer. The stabilizing effect of $\phi_{n}$ will be shown in detail in the next section, where we study the dynamics of our model.

Differentiating $\varsigma_{x}$ with respect to $\phi_{n}$ we obtain:

$$
\frac{d \varsigma_{x}}{d \phi_{n}}=\frac{1}{\gamma_{c}\left(\phi_{n}-1\right)^{2}}\left(\sigma+\gamma_{c}+\phi \gamma_{c}\right)>0
$$

Hence:

Corollary 1. the higher the degree of progressivity of the labor income tax, $\phi_{n}$, the steeper becomes the NKPC.

Notice that for $\phi_{n}=0$, the Phillips curve collapses to the standard NK forward looking Phillips curve. By closing the gap $\hat{x}_{t}$, the Central Bank is able to obtain an inflation rate equal to zero.

Here is some intuition for Corollary 1. Ceteris paribus, in order to produce more output, firms need more labor and the real wage must increase. If taxes on labor income are progressive, the increase in the real wage is followed by an increase in the marginal tax rate $\tau_{t}^{m}$ and the supply of labor increases less than in the basic NK model. Therefore, with respect to the standard NK model, to produce the same amount of output, firms must pay higher real wages at the cost of setting higher prices and therefore higher inflation. The NKPC, therefore, becomes steeper as $\phi_{n}$ increases.

All the results we obtain in this section derive from the fact that progressive taxation makes hours worked, and hence output, less sensitive to fundamentals (i.e. productivity and government spending shocks). This holds both in the flexible-price equilibrium and in a sticky-price equilibrium. With flexible prices this is quite clear from equation (27) where we see that a higher $\phi_{n}$ implies a smaller impact of productivity and government spending shocks to output. With sticky prices, as shown by equation (30) and the 
definition of $\varsigma_{x}$ it materializes through a higher sensitivity of marginal costs to economic fundamentals. The discrepancy between flexible-price output and the efficient one enters into the sticky-price equilibrium as a cost push shock in the determination of the inflation rate, as shown by equation (31). Hence, there is a trade-off: inflation stabilization and output stabilization to its efficient level cannot be simultaneously attained.

\subsection{The IS curve}

The reduced form solution of the model is given by the IS curve and the NKPC. In order to find the IS curve, we combine together the Euler equation (9), the aggregate resource constraint (18), the aggregate production function (23) and the aggregate labor supply (8). After some algebra we get:

$$
\hat{y}_{t}=E_{t} \hat{y}_{t+1}-\left(1-\gamma_{c}\right) E_{t} \Delta \hat{g}_{t+1}-\frac{\gamma_{c}}{\sigma}\left(\widehat{r}_{t}-E_{t}\left\{\hat{\pi}_{t+1}\right\}\right)
$$

we can rewrite the IS curve in terms of the welfare relevant output gap as follows:

$$
\hat{x}_{t}=E_{t} \hat{x}_{t+1}-\frac{\gamma_{c}}{\sigma}\left(\widehat{r}_{t}-E_{t}\left\{\hat{\pi}_{t+1}\right\}-\widehat{r}_{t}^{E f f}\right) .
$$

where $\widehat{r}_{t}^{E f f}$ is the interest rate that characterizes an efficient-frictionless economy.

\section{Dynamics}

In this section we study how the progressivity of the labor income tax affects the dynamics of the model. In particular, we look at how $\phi_{n}$ affects: (i) the conditions under which the rational expectation equilibrium is determinate, (ii) the responses of output and inflation to a technology, a government spending shock and a monetary shock.

We close the model by specifying an equation for the monetary authority. We assume that the Central Bank sets the short run nominal interest rate according to the following standard Taylor-type rule:

$$
\widehat{r}_{t}=\alpha_{\pi} \widehat{\pi}_{t}+\alpha_{y} \hat{x}_{t}+i s_{t} .
$$

where $i s_{t}$ is an exogenous monetary shock, modelled as an $\mathrm{AR}(1)$ process, i.e.,

$$
i s_{t}=\rho_{i} i s_{t-1}+\varepsilon_{t}^{i}
$$

where $\rho_{i}<1$ and $\varepsilon_{t}^{i}$ is a normally distributed serially uncorrelated innovation with zero mean and standard deviation $\sigma_{i}$. 


\subsection{Determinacy and the Taylor principle}

To assess the determinacy of the Rational Expectations Equilibrium (REE), we consider equation (32), we then substitute the Taylor rule (36) into the IS curve (35), together with the definition of the efficient interest rate. We then write the two structural equations in the following matrix format

$$
X_{t}=\mathbf{B} E_{t} X_{t+1}+\mathbf{A} u_{t}
$$

where vector $X_{t}$ includes the inflation rate $\pi_{t}$ and the output gap $x_{t}$. $u_{t}$ is a vector of all the shocks, i.e. $a_{t}, g_{t}, i s_{t}$. Determinacy of REE is obtained if the standard Blanchard and Kahn (1980) conditions are satisfied. Our model is isomorphic to the standard NK model, and matrix $B$ is exactly the same which characterizes the determinacy properties of the standard model. The only difference is due to the parameter $\phi_{n}$ indicating the degree of progressivity of the labor income tax which affects the slope of the NKPC. Therefore, following Woodford (2001, 2003, see chp. 4.2.2) the necessary and sufficient conditions for determinacy under a linear interest rate rule require:

$$
\alpha_{\pi}+\frac{(1-\beta)}{\kappa} \alpha_{y}>1
$$

where in our model $\kappa=\frac{\lambda \sigma+\gamma_{c}\left(\phi+\phi_{n}\right)}{\gamma_{c}\left(1-\phi_{n}\right)}$. We can therefore look at the effects of progressive taxation on the determinacy region. We can state the following:

Proposition 2. The effects of progressive taxation on the determinacy region. Let $\alpha_{\pi} \in[0, \infty), \alpha_{y} \in[0, \infty)$ and at least one different from zero. Then

$$
\frac{d\left(\frac{1-\beta}{\kappa}\right)}{d \phi_{n}}=-\gamma_{c}(1-\beta) \frac{\sigma+\gamma_{c}+\phi \gamma_{c}}{\lambda\left(\sigma+\phi_{n} \gamma_{c}+\phi \gamma_{c}\right)^{2}}<0
$$

which implies that the determinacy region shrinks in the parameter space $\left(\alpha_{\pi}, \alpha_{y}\right)$ as the degree of the progressive taxation increases

According to Proposition 2 progressive taxation on labor income shrinks the determinacy region. This means that for a given $\alpha_{y}$ condition (39) is satisfied for higher of $\alpha_{\pi}$.

In order to get some intuition about this result, suppose that, in the absence of any shock to fundamentals, there was an increase in the expected inflation. In the basic NK model a central bank that operates according to a Taylor rule must react by increasing the nominal interest rate more than 
proportionally than the rate of inflation. The real interest rate increases so that consumption and output decrease. If the reaction of the central bank is strong enough, it will be able to avoid self-fulfilling inflationary expectations. It is important to notice that when output decreases, real wages decrease as well.

In an economy with progressive taxation, taxes act as automatic stabilizers: when the central bank raises the real interest rate the net wage received by households increases and consequently the supply of labor hours decreases less than in the basic NK model. Output therefore decreases less, and the monetary authority to avoid self-fulfilling inflation has to use a more aggressive policy rule.

\subsection{Impulse Response Functions}

We now analyze how the dynamics of the log-linearized model depends on the parameter $\phi_{n}$ which characterizes the degree of progressivity of labor income taxation. In particular, we look at the implied dynamics of the main economic variables in response to a positive productivity shock, to a positive government spending shock and to a positive monetary shock.

We calibrate the model using the following parameters specification: ${ }^{10}$ as in Blanchard and Galì (2007) we set $\sigma=1, \phi=1$, and $\beta=0.99$; following Basu and Fernald (1997), the value added mark-up of prices over marginal cost is set equal to 0.2 . This generates a value for the price elasticity of demand, $\varepsilon=6$. Finally, firms probability to revise prices, $\varphi$, is set equal to $0.75 .{ }^{11}$ From the steady state we find that $\gamma_{c}=\frac{1+\eta(\varepsilon-1)}{\varepsilon}$. We set $\eta=0.7$ which, as in Guo and Lansing (1999) implies that in steady state the average income tax rate is equal to 0.3. The persistence of technology, Government spending and monetary policy shocks are respectively: $\rho_{a}=\rho_{g}=\rho_{i}=0.9$. The three shocks are calibrated to have $1 \%$ standard deviation. We consider the case in which the monetary authority implements the standard Taylor (1993) rule, and therefore we set $\alpha_{\pi}=1.5$ and $\alpha_{y}=0.5 / 4$. None of the qualitative results depends on the calibration values chosen.

Figures 1-3 show the responses of inflation, output, labor hours and real wages to a positive technology shock, to a positive Government spending shock and to a positive monetary shock for different values of $\phi_{n}$.

- Figures 1-3 about here -

\footnotetext{
${ }^{10}$ None of the qualitative results are affected by the parameters' choice.

${ }^{11}$ See for example Galì (2008) among others.
} 
Figure 1 shows that, in response to a positive technology shock, output and real wages increase on impact while inflation and labor hours decrease. They all return to their initial level after almost thirty periods. The negative response of labor hours to a technology shock is consistent with much of the recent empirical evidence on the effects of technology shocks (see, for example, Galì and Rabanal, 2004 and, more recently, Canova et al. 2010). This is due to the presence of price stickiness. Indeed, even though all firms experience a decline in their marginal cost, only a fraction of them are able to adjust their prices downwards in the short run. Accordingly, the aggregate price level declines, and aggregate demand rises, less than proportionally with the increase in productivity. Consequently, a decline in aggregate hours worked occurs.

It is quite evident, from the impulse response functions, that in response to a technology shock progressive taxation acts as an automatic stabilizer for output and inflation. The higher is $\phi_{n}$, the lower is the effect of the technology shock on output, and inflation. Conversely, the higher is $\phi_{n}$, the higher the effect on labor hours. ${ }^{12}$

The effects of government spending shocks are shown in Figure 2. As in the standard NK model the effect on output, hours and real wages is positive. This results however depends on a series of forces working on different directions. A government spending shock directly increases aggregate demand but has also a negative wealth effect on consumption induced by the need to pay higher taxes to finance spending. Since consumption and leisure in this model are normal goods, the negative wealth effect generates also an increase in labor supply. Because of sticky prices this implies higher output and higher inflation. Progressive taxation dampens the positive impact of the shock on output and labor hours. This happens because with progressive taxation higher real wages means higher taxes and this has negative retroactive effect on labor supply. Notice however that the higher is $\phi_{n}$ the higher is the increase in inflation. The reason is that, relatively to the case of $\phi_{n}=0$, firms must pay higher real wages to produce the same amount of output. This implies higher prices and therefore higher inflation.

The effects of a positive monetary shock are shown in Figure $3 .{ }^{13}$ A

\footnotetext{
${ }^{12}$ The reason is that the technology shock enters the NKPC and that the NKPC becomes steeper as $\phi_{n}$ increases. This implies that with a progressive labor income taxation actual output increases less than in the standard NK model. That, in turn, induces a stronger decline in aggregate employment.

${ }^{13}$ Some caution is required when we interpret the impulse response functions of the monetary policy shocks. The large effects that we find are largely a consequence of the fact that, for simplicity, being our exercise purely qualitative, all shocks are calibrated in the same way. This type of calibration for a monetary shock is not very realistic.
} 
positive monetary shock, which increases the nominal interest rate, implies a decrease in consumption and aggregate demand, which is then followed by a decrease of inflation, output, hours and real wages. Notice that, progressive taxation dampens the impact of shocks on output, hours and employment. The higher is $\phi_{n}$ the higher is the decrease in inflation.

Overall, we can claim that progressive taxation seems to have a stabilizing effect on the economic activity.

\section{Quantitative Evaluation}

An interesting implication of our model is that progressive taxation acts as an automatic stabilizer, reducing the volatility of relevant variables like output, labor hours and inflation in response to macroeconomic shocks. In order to check whether our model is consistent with the data, in this section we provide a quantitative assessment of the relationship between progressive taxation and macroeconomic volatility. To this purpose we regress, for a sample of 24 OECD countries, various measures of volatility on an indicator of tax progressivity and other control variables.

The first issue that arises in our empirical exercise is to provide a reliable measure of the degree of progressivity of the tax system which in our model is given by the parameter $\phi_{n}$. We start by considering the marginal tax rate given by equation $(4)^{14}$. At the steady state

$$
\tau_{m}=\tau+\eta \phi_{n}
$$

Dividing by the average tax rate $\tau$ and considering that, at the steady state, $\tau=1-\eta$, equation (41) becomes

$$
\phi_{n}=\frac{1-\eta}{\eta}\left(\frac{\tau_{m}}{\tau}-1\right) .
$$

Notice that the parameter $\phi_{n}$ is the product of two components: the ratio $\frac{1-\eta}{\eta}$ where $\eta$ is the average tax rate in the long run, and the ratio $\frac{\tau_{m}}{\tau}$ which

According to recent estimates for the US economy by Smets and Wouters (2007), the quarterly standard deviation of the monetary shocks ranges from $0.2 \%$ for the period 1966:1-1979:2 to 0.12\% for the period 1984:1-2004:4, while Benati and Surico (2009), who impose equilibrium indeterminacy for the pre-October 1979 period and determinacy for the post-Volcker stabilization periods, find a variance of the monetary disturbance equal to $0.492 \%$.

Once we use these types of values for the calibration, the monetary policy shock is not very important, although progressive taxation still has a stabilizing effect for the economy.

${ }^{14}$ As we mentioned above, following Guo and Lansing (1998) (1999), we define the margial tax rate as $\frac{\partial\left(\tau_{t} Y_{n, t}\right)}{\partial Y_{n, t}}$. 
is the elasticity of the tax rate to the relevant tax base (which in our case is the ratio between steady state labor income $Y_{n}$ and actual labor income $\left.Y_{n, t}\right)$. We evaluate the first component by taking, for a sample of 24 OECD countries, the mean of the average tax rates over the period 1999-2009.

Data on the second component, which require a careful analysis of each country tax legislation, are not usually available, but the Economics Department of the OECD, in order to provide estimates of cyclically adjusted budget balances, has occasionally produced estimates of tax elasticities. The last official estimate dates back to $1999^{15}$, but fortunately tax elasticities have been more recently re-estimated and re-specified by Andrè and Girouard (2005).

In table 2, we report the elasticities of the income tax to earnings provided by Girouard and Andrè (2005) ${ }^{16}$ together with the mean of the average tax rates over the period 1999:1-2009:4. These two sets of data are used to compute the parameter $\phi_{n}$, which is also reported in table 2 . In the same table we also report the standard deviation of detrended GDP, the standard deviation of labor hours and the standard deviation of inflation for our sample $\operatorname{period}^{17}$.

- Figures 4 - 6 about here -

In Figures 4 - 6 the standard deviations of output, inflation and labor hours are plotted against the parameter $\phi_{n}$ for our group of countries. In Table 3 below, we report our OLS cross section estimates. Output volatility $\sigma_{y}$, hours volatility $\sigma_{h}$ and inflation volatility $\sigma_{\pi}$ are regressed on a constant $C$, on our measure of tax progressivity $\phi_{n}$, and on a set of controls that have been found in the literature to be important determinants of macroeconomic volatility. In particular, we use, as additional regressors, the standard deviation of Government consumption, $\sigma_{G}$, the standard deviation of the terms

\footnotetext{
${ }^{15}$ See OECD Economic Outlook, No. 66. Detailed results OECD's cyclically adjusted budget balances are reported by Van den Noord (2000).

${ }^{16}$ We consider all the countries for which data have been provided by Girouard and Andrè (2005), except for Luxemburg and Iceland, two countries that, being much smaller than all the others, clearly show a very anomalous behavior. Girouard and Andrè (2005) provide various measures of elasticities depending on the relevant tax base. We use the earnings elasticity because it is the most appropriate to our model which studies the progressivity of labor income taxes.

${ }^{17}$ Precisely, as a measure of output gap volatility we use the standard deviation of the $\ln ($ real $G D P)$. As a measure of the volatility of inflation we use the standard deviation of $\Delta \ln C P I$. Both variables are detrended using the Hodrick and Prescott filter with a smoothing parameter $\lambda=1600$. The standard deviation of labor hours is measured by taking the log of the average annual hours worked (quarterly data are not available) filtered using the Hodrick-Prescott filter with $\lambda=100$.
} 
of trade $\sigma_{\text {tot }}$ and two measures of labor market institutions. ${ }^{18}$ As an indicator of firing costs we use the strictness of employment protection, EPL, computed by the OECD and as an indicator of the degree of centralization in labor contracts, the union density $U D$, also computed by the OECD. Both variables are averaged over the sample period. As recently shown by Abbritti and Weber (2010), Campolmi and Faia (2011), Merkl and Schmitz (2011) and Rumler and Scharler (2009) labor market institutions seem to play an important role in determining macroeconomic volatility, especially in the Euro Area countries.

To control for size effects we use the log of real GDP, $Y$, averaged over the sample period. We also include a dummy variable $D U E$ which takes the value of 1 if a country belongs to the European Union and the value of 0 otherwise. This dummy variable is meant to capture all the unexplained factors, besides those explicitly included among the regressors that are likely to influence volatility in an area, such as the European Union, that is quite homogenous from the institutional point of view.

\footnotetext{
${ }^{18}$ The standard deviation of terms of trade and that of government expenditure are computed similarly to the standard deviation of real GDP. As a measure of government expenditure we use quarterly data on government consumption. Quarterly terms of trade are defined as the ratio between the deflator for exports and the deflator for imports of goods and services. Both variables are filtered using the Hodrik-Prescott filter with $\lambda=1600$. The regression having labor hours as dependent variable uses the same variables with annual frequency, filtered using the Hodrik-Prescott filter with $\lambda=100$. All the data come from the OECD database.
} 


\begin{tabular}{|c|c|c|c|c|c|c|}
\hline \multirow{3}{*}{ Regressors } & \multicolumn{6}{|c|}{ Dependent variables } \\
\hline & \multicolumn{2}{|c|}{$\sigma_{y}$} & \multicolumn{2}{|c|}{$\sigma_{H}$} & \multicolumn{2}{|c|}{$\sigma_{\pi}$} \\
\hline & (1) & $(2)$ & (1) & $(2)$ & (1) & $(2)$ \\
\hline$C$ & $\begin{array}{l}0.58 \\
(0.52)\end{array}$ & $\begin{array}{c}1.49^{* * *} \\
(5.22)\end{array}$ & $\begin{array}{l}1.63^{*} \\
(1.77)\end{array}$ & $\begin{array}{l}1.31^{* * *} \\
(6.59)\end{array}$ & $\begin{array}{c}0.02 \\
(0.037)\end{array}$ & $\begin{array}{l}0.44^{* * *} \\
(4.74)\end{array}$ \\
\hline$D U E$ & $\begin{array}{c}0.89^{* *} \\
(3.70)\end{array}$ & $\begin{array}{c}0.86^{* * *} \\
(4.01)\end{array}$ & $\begin{array}{l}0.14 \\
(0.66)\end{array}$ & - & $\begin{array}{c}0.004 \\
(0.33)\end{array}$ & - \\
\hline$\phi_{n}$ & $\begin{array}{c}-1.21^{*} \\
(-1.72)\end{array}$ & $\underset{(-1.91)}{-1.16^{*}}$ & $\begin{array}{c}-1.60^{* *} \\
(-2.56)\end{array}$ & $\begin{array}{l}-1.30^{* *} \\
(-2.37)\end{array}$ & $\begin{array}{c}-0.66^{*} \\
(-1.90)\end{array}$ & $\begin{array}{c}-0.56^{* *} \\
(-2.03)\end{array}$ \\
\hline$E P L$ & $\begin{array}{l}-0.29 \\
(-1.94)\end{array}$ & $\begin{array}{c}-0.27^{* *} \\
(-2.13)\end{array}$ & $\begin{array}{l}0.20 \\
(1.56)\end{array}$ & - & $\begin{array}{c}0.063 \\
(0.84)\end{array}$ & - \\
\hline$U D$ & $\begin{array}{l}0.01 \\
(1.34)\end{array}$ & - & $\begin{array}{c}-0.001^{* *} \\
(2.60)\end{array}$ & $\begin{array}{l}-0.01^{*} \\
(-1.90)\end{array}$ & $\begin{array}{c}0.000 \\
(0.19)\end{array}$ & - \\
\hline$\sigma_{G}$ & $\begin{array}{c}0.27^{* *} \\
(2.46)\end{array}$ & $\begin{array}{c}0.22^{* *} \\
(2.30)\end{array}$ & $\begin{array}{c}-0.002 \\
(0.34)\end{array}$ & - & $\begin{array}{c}0.29^{* * * *} \\
(5.26)\end{array}$ & $\begin{array}{c}0.28^{* * *} \\
(5.96)\end{array}$ \\
\hline$\sigma_{t o t}$ & $\begin{array}{l}0.01 \\
(0.44)\end{array}$ & - & $\begin{array}{l}-1.57 \\
(-0.73)\end{array}$ & - & $\begin{array}{c}0.001 \\
(0.91)\end{array}$ & - \\
\hline$Y$ & $\begin{array}{l}0.04 \\
(0.71)\end{array}$ & - & $\begin{array}{l}-0.03 \\
(-0.68)\end{array}$ & - & $\begin{array}{c}0.001 \\
(0.21)\end{array}$ & - \\
\hline$R^{2}$ & 0.65 & 0.61 & 0.52 & 0.30 & 0.72 & 0.66 \\
\hline
\end{tabular}

Significance: ${ }^{* * *} 1 \% ;{ }^{* *} 5 \% ;{ }^{*} 10 \%$. $t$-statistics in parenthesis

\section{Table 3.}

For every dependent variable we first report the regression where all the explanatory variables are included, and then the regression where only the variables with a significance level below $10 \%$ are left. In the first two columns of table 3 we report the regressions of the standard deviation of output. Notice that, our indicator of tax progressivity is significant and enters with a negative sign. The other two significant variables are the volatility of government expenditure, $\sigma_{g}$, and the strictness of employment protection, EPL. The former enters with a positive sign, while the latter enters with a negative sign. This is in line with the literature quoted above that emphasizes the negative relationship between $E P L$ and output volatility. The union density indicator, $U D$, the standard deviation of the terms of trade, $\sigma_{\text {tot }}$ and the average real GDP, $Y$ instead, are not significant. Also the dummy variable $D U E$ enters significantly our output volatility regression indicating that, ceteris paribus, European countries, for the period 1999-2009 have shown higher volatility than the other OECD countries. ${ }^{19}$

\footnotetext{
${ }^{19}$ The inclusion of the dummy $D U E$ is crucial in determining the significance also of $\phi_{n}$ and EPL.
} 
In the second set of regressions the dependent variable is the volatility of labor hours. Again our indicator of tax progressivity shows a significant negative relationship with hours volatility. The dummy variable $D U E$ however is not significant. In the final regression the only significant explanatory variables besides $\phi_{n}$ is the union density indicator, $U D$, which enters with a negative sign, meaning that a more centralized labor market reduces the volatility of labor hours.

Finally, the last two columns of table 3, report the inflation volatility regressions. Also the standard deviation of inflation is negatively related to tax progressivity, as we show in the theoretical model. Again, the European dummy $D U E$ is not significant and the only other significant explanatory variable, in accordance with the results obtained by Merkl and Schmitz (2011), is the standard deviation of government expenditure.

Overall, the estimates presented above are consistent with the results of our model. Although some caution is necessary in interpreting these results since they are based on a limited amount of available data, they provide, nevertheless, a clear indication that progressive taxation works as an automatic stabilizer, and therefore should not be ignored in macroeconomic policy evaluation.

\section{Optimal Monetary Policy}

In order to analyze the consequences of progressive taxation for optimal monetary policy, we now derive the loss function of the Central Bank. To this purpose, we follow Benigno and Woodford (2005) and we derive a second order approximation of the household utility function under a distorted steady state. $^{20}$ The welfare-loss function can then be expressed as

$$
\begin{aligned}
& \min _{\left\{x_{t}, \pi_{t}\right\}}-\frac{1}{2} E_{0} \sum_{t=0}^{\infty} \beta^{t}\left[q_{x} \hat{x}_{t}^{2}+q_{\pi} \pi_{t}^{2}\right]+T_{t_{0}}+\text { t.i.p. }+O\left(\|\xi\|^{3}\right) \\
& \text { s.t. } \\
& \hat{\pi}_{t}=\beta E_{t} \hat{\pi}_{t+1}+\kappa \hat{x}_{t}+\kappa u_{t}
\end{aligned}
$$

where $q_{x}$ and $q_{\pi}$ are complicated convolution parameters depending on the structural parameters of the model. This specific structure of these parameters, together with the derivation of the loss function, are reported in

\footnotetext{
${ }^{20}$ As shown by Benigno and Woodoford (2005) in the face of large distortions the presence of a linear term in (43) would require the use of a second-order approximation to the equilibrium condition connecting output gap and inflation. The technical Appendix (A.1) shows in detail how we derive the loss-function reported below.
} 
Appendix A.1. ${ }^{21}$ Notice that the linear term $\hat{x}_{t}$ captures the fact that any increase in output positively affects welfare. Notice also that, by following the methodology developed by Benigno and Woodford (2005), the Central Bank's problem has the convenient linear-quadratic form even with a distorted steady state.

\subsection{Discretion}

If the Central Bank cannot credibly commit in advance to a future policy action or to a sequence of future policy actions, then the optimal monetary policy is discretionary, in the sense that the policy makers choose in each period the value to assign to the policy instrument $i_{t}$. The Central Bank minimizes the welfare-based loss function, subject to the Phillips curve, taking all expectations as given. Therefore:

$$
\begin{aligned}
& \min _{\left\{x_{t}, \pi_{t}\right\}}-\frac{1}{2}\left[\pi_{t}^{2}+\alpha_{x} \hat{x}_{t}^{2}\right]+F_{t} \\
& \text { s.t. } \\
\pi_{t}= & \kappa x_{t}+f_{t}
\end{aligned}
$$

where $f_{t}=\beta E_{t} \pi_{t+1}+\kappa u_{t}, \alpha_{x}=\frac{q_{x}}{q_{\pi}}$ and $F_{t}=E_{0} \sum_{i=1}^{\infty} \beta^{t}\left[\alpha_{x} x_{t+i}^{2}+\pi_{t+i}^{2}\right]$.

Solving the problem we find that optimality requires the following targeting rule:

$$
\hat{x}_{t}=-\frac{\kappa\left(\phi_{n}\right)}{\alpha_{x}\left(\phi_{n}\right)} \pi_{t}
$$

Proposition 3. A unit increase in inflation requires a decrease in the output gap which is not independent from the degree of progressivity of the labor income tax.

To show our result in a more readable and tractable way, we now consider the effect of a technology shock. In order to do so we assume that public expenditure is always zero. This implies that $\hat{g}_{t}=0$ for each $t .^{22}$ In this case

$$
\frac{\kappa}{\alpha_{x}}=\frac{\left(1+\phi+\Phi \phi_{n}\right) \varepsilon}{\left((1+\phi)\left(\left(1-\phi_{n}\right)+\phi_{n} \Phi\right)+\phi_{n} \Phi\right)}
$$

\footnotetext{
${ }^{21}$ As shown by Benigno and Woodford (2005), the term $T_{t_{0}}$ is a transitory component, defined in the appendix, which is predetermined at the time of the policy choice.

${ }^{22}$ For the same reason we also assume that $\sigma=1$. Results are not affected by these simplifying hyphotesis.
} 
where $\Phi=\frac{\varepsilon-\eta(\varepsilon-1)}{\varepsilon}<1$ is the steady state distortion. Taking the derivative of $\frac{\kappa}{\alpha_{x}}$ with respect to $\phi_{n}$ we obtain:

$$
\frac{d\left(\frac{\kappa}{\alpha_{x}}\right)}{d \phi_{n}}=\varepsilon(1-\Phi) \frac{(\phi+1)^{2}}{\left(\phi-\phi_{n}+2 \phi_{n} \Phi+\phi_{n} \phi(\Phi-1)+1\right)^{2}}>0
$$

Corollary 2. A unit increase in inflation requires a decrease in the output gap. Such decrease is greater the higher is the degree of progressivity of the tax system.

Substituting (44) in the IS curve we finally find the optimal interest rate, which is given by:

$$
\widehat{r}_{t}^{*}=\widehat{r}_{t}^{E f f}+\left(1+\frac{\kappa\left(1-\rho_{a}\right)}{\alpha_{x} \rho_{a}}\right) E_{t} \pi_{t+1}
$$

then:

Proposition 4. With progressive taxation the Central Bank implements the Taylor principle, i.e., the monetary authority increases the nominal interest rate more than proportionally with respect to the increase in the inflation rate. Since inflation falls down in response to a positive technology shock, this means that the monetary authority responds procyclically to a positive technology shock. ${ }^{23}$

In the technical appendix (A.2) we show that

$$
\frac{d\left(1+\frac{\kappa\left(1-\rho_{a}\right)}{\alpha_{x} \rho_{a}}\right)}{d \phi_{n}}>\mathbf{0}
$$

Corollary 3. The higher the degree of the progressivity of the labor income tax the more aggressive is optimal policy in response to a technology shock.

\footnotetext{
${ }^{23}$ Symmetrically, when the shock is a government spending shock or a cost-push shock, which rise inflation on impact, the monetary authority responds by increasing the nominal interest rate.
} 
The interest rate rule given by (46) is isomorphic to the rule derived by Clarida et al (1999). Bullard and Mitra (2002) show that this type of rule is more prone to indeterminacy than a rule targeting contemporaneous inflation. As in Bullard and Mitra (2002), in order to guarantee determinacy, in fact, the optimal coefficient $\alpha_{\pi}=\left(1+\frac{\kappa\left(1-\rho_{a}\right)}{\alpha_{x} \rho_{a}}\right)$ must lie in the following interval $\left(1,1+\frac{2(1+\beta)}{\kappa}\right)$ and therefore there is also an upper bound on $\alpha_{\pi}{ }^{24}$ In the standard model, the upper bound is not considered a problem since it is quite big for the standard parameters. Notice however that in this model, $\alpha_{\pi}$ is an increasing function of $\phi_{n}$, while the upper bound which guarantees determinacy, $1+\frac{2(1+\beta)}{\kappa}$ is a decreasing function of $\phi_{n}$. This means that it is possible that the upper bound for determinacy is lower than the optimal response to inflation and the rule is not implementable. ${ }^{25}$

It is possible however to solve this problem by using the alternative specification proposed by Evans and Honkapohja (2003). Using (44), the IS curve and the NKPC we can apply this alternative specification also to our model and get the following optimal rule

$$
\widehat{r}_{t}^{*}=\left(1+\frac{\kappa \beta}{\alpha_{x}+\kappa^{2}}\right) E_{t} \pi_{t+1}+E_{t} x_{t+1}+\frac{\kappa}{\alpha_{x}+\kappa} a_{t}
$$

As we show in Appendix A3, also in our economy with progressive taxation this rule insures determinacy of the REE.

In order to evaluate the welfare implications of monetary policy, we now compute the unconditional welfare-loss. Combining the NKPC with equation (44) and iterating forward we get:

$$
\pi_{t}=\alpha_{x} \varsigma_{a} \Psi a_{t}
$$

where $\Psi=\frac{1}{\kappa^{2}+\alpha_{x}\left(1-\beta \rho_{a}\right)}$ and $\varsigma_{a}=\lambda \frac{(1+\phi)(1-\Phi)}{\left(1-\phi_{n}\right) q_{x}}$. Combining then (49) with (44) we obtain:

$$
\hat{x}_{t}=-\kappa \varsigma_{a} \Psi a_{t} .
$$

\footnotetext{
${ }^{24}$ Remember that for simplicity we set $\sigma=1$. Results are not affected qualitatively by this choice.

${ }^{25}$ It is not possible to find a clear analytical condition on $\phi_{n}$ and therefore we resort to numerical simulations. We find that for the standard parameterization used in this paper, the coefficient of optimal rule, i.e. $\alpha_{\pi}$ is always below its lower bound, for empirical realistic values of $\phi_{n}$. However, $\alpha_{\pi}$ becomes lower than the upper bound when considering lower values of $\rho_{a}$. For example, with $\rho_{a}=0.5$ the optimal coefficient $\alpha_{\pi}$ becomes greater than the upper bound and the REE is indeterminate for sufficient high value of $\phi_{n}\left(\phi_{n}>0.53\right.$ is sufficient). We thank an anonymous referee for pointing out this point and for suggesting the alternative rule proposed by Evans and Honkapoja (2003).
} 
If we now substitute (49) and (50) in the loss-function we obtain the unconditional welfare-loss under discretion,

$L_{D}=\frac{1}{2}\left[\operatorname{Var}\left(\pi_{t}\right)+\alpha_{x} \operatorname{Var}\left(\hat{x}_{t}\right)\right]=\frac{1}{2}\left[\left(\alpha_{x} \varsigma_{a} \Psi\right)^{2} \operatorname{Var}\left(a_{t}\right)+\alpha_{x}\left(\kappa \varsigma_{a} \Psi\right)^{2} \operatorname{Var}\left(a_{t}\right)\right]$.

\subsection{Gains from Commitment}

We now assess the welfare gains that the Central Bank may obtain by committing to a state-contingent rule of the kind studied by Clarida et al. (1999):

$$
\hat{x}_{t}^{c}=-\omega a_{t}
$$

Under the state-contingent rule (52) inflation evolves according to:

$$
\pi_{t}^{c}=\frac{\varsigma_{a}-\kappa \omega}{1-\beta \rho_{a}} a_{t}
$$

and the NKPC implies

$$
\pi_{t}^{c}=\frac{\kappa}{1-\beta \rho_{a}} \hat{x}_{t}^{c}+\frac{\varsigma_{a}}{1-\beta \rho_{a}} a_{t}
$$

this means that under constrained commitment to the rule (52) a $1 \%$ contraction in the output gap $\hat{x}_{t}^{c}$ reduces inflation $\pi_{t}^{c}$ by the factor $\frac{\kappa}{1-\beta \rho_{a}}$. Under discretion the same reduction in the output gap produces a fall in $\pi_{t}$ only equal to $\kappa<\frac{\kappa}{1-\beta \rho_{a}}$. Under constrained commitment, therefore, the gains from reducing inflation are higher than the ones under discretion. ${ }^{26}$ As in Clarida et al (1999), the problem of the Central Bank is to choose the optimal value of the feedback parameter $\omega$ by minimizing the welfare-loss subject to equation (54). The first order conditions imply:

$$
\hat{x}_{t}^{c}=-\frac{\kappa}{\alpha_{x}^{c}} \pi_{t}^{c}
$$

where $\alpha_{x}^{c}=\alpha_{x}\left(1-\beta \rho_{a}\right)<\alpha_{x}$. The equilibrium solution for $\hat{x}_{t}^{c}$ and $\pi_{t}^{c}$ are obtained by combining (55) and (54) and imply

$$
\begin{aligned}
\hat{x}_{t}^{c} & =-\kappa \varsigma_{a} \Psi^{c} a_{t} \\
\pi_{t}^{c} & =\alpha_{x}^{c} \varsigma_{a} \Psi^{c} a_{t}
\end{aligned}
$$

\footnotetext{
${ }^{26}$ It is worth to notice, that the unconstrained Pareto optimum would dominate the rules analyzed under constrained commitment. As shown by Evans and Honkapohja (2006) the rule obtained under unconstrained commitment is always determinate.
} 
where $\Psi^{c}=\frac{1}{\kappa^{2}+\alpha_{x}^{c}\left(1-\beta \rho_{a}\right)}$. Finally, to evaluate welfare we can compute the unconditional welfare-loss, which is given by

$L_{C}=\frac{1}{2}\left[\operatorname{Var}\left(\pi_{t}\right)+\alpha_{x} \operatorname{Var}\left(\hat{x}_{t}\right)\right]=\frac{1}{2}\left[\left(\alpha_{x}^{c} \varsigma_{a} \Psi^{c}\right)^{2} \operatorname{Var}\left(a_{t}\right)+\alpha_{x}\left(\kappa \varsigma_{a} \Psi^{c}\right)^{2} \operatorname{Var}\left(a_{t}\right)\right]$

As a measure of the welfare gains implied by commitment we take the ratio between the unconditional loss under discretion $L_{D}$ and the unconditional loss under commitment $L_{C}$. This measures the welfare loss from moving from a constrained commitment equilibrium to a discretionary equilibrium.

$$
W_{G}=\frac{L_{D}}{L_{C}}=\frac{\left(\kappa^{2}+\alpha_{x}^{c}\left(1-\beta \rho_{a}\right)\right)^{2}\left(\alpha_{x}^{2}+\alpha_{x}\left(\kappa \varsigma_{a} \Psi\right)^{2}\right)}{\left(\kappa^{2}+\alpha_{x}\left(1-\beta \rho_{a}\right)\right)^{2}\left(\alpha_{x}^{c 2}+\alpha_{x}\left(\kappa \varsigma_{a} \Psi^{c}\right)^{2}\right)}
$$

Notice that with $\rho_{a}=0$ the welfare gains are nil. In this case the central bank is not able to improve the performance of monetary policy by conditioning future expectation, since the effect of the shock last for just one period. The more persistent the shocks, therefore, the higher are the welfare gains from commitment.

Figure 7 shows what happens to the welfare gains when the parameter $\phi_{n}$ increases.

- Figure 7 about here -

As we can see from this graph, the more progressive are labor income taxes, the lower are the welfare gains from commitment. The intuition is straightforward. Remember that by committing to a state contingent rule as in (52) the monetary authority yields a more stable inflation. As we show in section 3, however, a progressive labor income tax has a stabilizing effect. Therefore, in economies characterized by a high $\phi_{n}$, the need for stabilizing inflation is not very high, and the gains from commitment deriving from stabilizing inflation become lower as $\phi_{n}$ increases.

\section{Conclusions}

We introduce progressive taxation on labor income in a New Keynesian model and we study the dynamics of the model and the optimal monetary policy both under discretion and under commitment to a state-contingent rule. We find that progressive taxation on labor income introduces a trade-off between 
output and inflation stabilization. As a consequence, the NKPC is affected by technology and demand shocks. Interestingly, the NKPC becomes steeper the higher is the degree of the progressivity of the labor income tax.

Another important result is the stabilizing role played by progressive taxation. The more progressive is the tax system, the smaller is the response of the economy to technology, government spending, and monetary policy shocks. This in turn implies a negative relationship between output, labor hours and inflation volatility and the degree of progressivity of labor income taxation. The results of the model are in line with available evidence.

We finally show that progressive labor income taxation affects the prescriptions for the optimal discretionary monetary policy and we find that the welfare gains from commitment decrease the more progressive is the labor income tax.

Progressive taxation is a common feature, especially in the industrialized world. Given the many consequences that this important institutional feature of modern economies, our model suggests that Dynamic New Keynesian models should not ignore the tax structure if they want to provide a satisfactory interpretation of the dynamics of contemporary economies and the effects of monetary policy. More in general, it suggests that the working of automatic stabilizers, a long neglected issued in modern macroeconomics, should receive renewed attention. 


\section{References}

Abbritti, M. and S. Weber (2010). Labor market institutions and the business cycle. unemployment rigidities versus real wage rigidities. Working paper series n. 1183, European Central Bank.

Andrés J. and Domenech R. (2006). Automatic stabilizers, fiscal rules and macroeconomic stability. European Economic Review 50(6), 14871506 .

Andrés J., Domenech R. and Fatas A. (2008). The stabilizing role of government size. Journal of Economic Dynamics and Control 32, 571-593.

Auerbach A. (2002). Is there a role for discretionary fiscal policy? NBER Working Papers 9306, National Bureau of Economic Research.

Auerbach Alan J. and Feenberg D. (2000). The significance of federal taxes as automatic stabilizers. Journal of Economic Perspectives 14(3), 3756 .

Ball L. and Romer D. (1991). Sticky prices as coordination failure. American Economic Review 81(3), 539-552.

Basu S. and J. Fernald (1997). Returns to scale in u.s. production: Estimates and implications. Journal of Political Economy 105(2), pages 249-83.

Benati, L. and P. Surico (2009). VAR analysis and the great moderation. The American Economic Review 99, 1636-1652.

Benigno, P. and M. Woodford (2005). Inflation stabilization and welfare: The case of a distorted steady state. Journal of the European Economic Association 3(6), 1-52.

Blanchard, O. and J. Galí (2007). Real wage rigidities and the new keynesian model. Journal of Money, Credit and Banking 39, 35-65.

Blanchard, O. J. and C. M. Kahn (1980). The solution of linear difference models under rational expectations. Econometrica 48, 1305-1311.

Blanchard, O. J. and N. Kiyotaki (1987). Monopolistic competition and the effects of aggregate demand. American Economic Review 7r, 647666.

Bullard, J. and K. Mitra (2002). Learning about monetary policy rules. Journal of Monetary Economics 49(6), 1105-1129.

Calvo, G. A. (1983). Staggered prices in a utility-maximising framework. Journal of Monetary Economics 12, 383-398. 
Campolmi, A. and E. Faia (2011). Labor market institutions and inflation volatility in the euro area,. Journal of Economic Dynamics and Control 35(5), 793-812.

Canova F., Salido L. and Michelacci C. (2010). The effects of technology shocks on hours and output: A robustness analysis. Journal of Applied Econometrics 25(5), 755-773.

Clarida, R., J. Galí, and M. Gertler (1999). The science of monetary policy: A new keynesian perspective. Journal of Economic Literature 37, 16611707.

Clarida, R., J. Galí, and M. Gertler (2002). A simple framework for international monetary policy analysis. Journal of Monetary Economics 49(5), 879-904,.

Collard, F. and H. Dellas (2005). Tax distortions and the case for price stability. Journal of Monetary Economics 52, 249-273.

Dolls M., F. Fuest and A. Peichl (2010). Automatic stabilizers and economic crisis: US vs. Europe. NBER Working Papers.

Edge, R. M. and J. B. Rudd (2007). Taxation and the Taylor principle. Journal of Monetary Economics 54, 2554-2567.

Evans, G. W. and S. Honkapohja (2003). Expectations and the stability problem for optimal monetary policies. Review of Economic Studies 70, 807-824.

Evans, G. W. and S. Honkapohja (2006). Monetary policy, expectations and commitment. Scandinavian Journal of Economics 108(1), 15-38.

Fatás A. and Mihov I. (2001). Government size and automatic stabilizers: International and intranational evidence. Journal of International Economics 55, 3-28.

Galì, J. (2008). Monetary Policy, Inflation and the Business Cycle (1 ed.). Princeton and Oxford: Princeton University Press.

Galí, J. and P. Rabanal (2004). Technology shocks and aggregate fluctuations: How well does the RBC model fit postwar U.S. data? In M. Gertler and K. Rogoff (Eds.), NBER Macroeconomics Annual, pp. 225-288. Cambridge, MA: The MIT Press.

Galì J. (1994). Government size and macroeconomic stability. European Economic Review 38(1), 117-132.

Girouard N. and André C. (2005). Measuring cyclically-adjusted budget balances for OECD countries. OECD Economics Department Working Papers 434, OECD, Economics Department. 
Gnocchi, S. (2009). Non-atomistic wage setters and monetary policy in a new keynesian framework. Journal of Money, Credit and Banking 41(8), 1613-1630.

Guo, J. T. (1999). Multiple equilibria and progressive taxation of labor income. Economics Letters 65, 97-103.

Guo, J.-T. and K. J. Lansing (1998). Indeterminacy and stabilization policy. Journal of Economic Theory 82, pages 481-490,.

Heer B. and A. Maussner (2006). Business cycle dynamcis of a new keynesian overlapping generation model with progressive income taxation. Cesifo Working paper No. 1692.

Kleven H. J. and Kreiner C.T. (2003). The role of taxes as automatic destabilizers in new keynesian economics. Journal of Public Economics 87, $1123-1136$.

Mattesini, F. and L. Rossi (2009). Optimal monetary policy in economies with dual labor markets. Journal of Economic Dynamics and Control 33, 1469-1489.

Merkl, C. and T. Schmitz (2011). Macroeconomic volatilities and the labor market: First results from the euro experiment. European Journal of Political Economy vol. 27(1), 44-60.

Rotemberg, J. J. and M. Woodford (1997). An optimization-based econometric framework for the evaluation of monetary policy. In J. J. Rotemberg and B. S. Bernanke (Eds.), NBER Macroeconomics Annual 1997, pp. 297-346. Cambridge, MA, The MIT Press.

Rumler, F. and J. Scharler (2009). Labor market institutions and macroeconomic volatility in a panel of OECD countries. Working Paper Series 1005, European Central Bank.

Schmitt-Grohé, S. and M. Uribe (2007). Optimal simple and implementable monetary and fiscal rules. Journal of Monetary Economics 54, 1702-1725.

Schmitt-Grohé, S. and M. Uribe (forthcoming). Optimal, simple, and implementable monetary and fiscal rules. Journal of Monetary Economics.

Smets, F. and R. Wouters (2007). Shocks and frictions in US business cycles: A bayesian DSGE approach. American Economic Review 97(3), 586-606.

Taylor, J. B. (1993). Discretion versus policy rules in practice. CarnegieRochester Conference Series on Public Policy 39, 195-214. 
Van den Noord, P. (2000). The size and role of automatic fiscal stabilizers in the 1990s and beyond. OECD, Economics Department, Working Paper, No. 230, Paris.

Vanhala, J. (2006). Labour taxation and shock propagation in a new keynesian model with search frictions. Bank of Finland Research Discussion Papers, 12.

Woodford, M. (2001). The Taylor rule and optimal monetary policy. American Economic Review Papers and Proceedings 91, 232-237.

Woodford, M. (2003). Interest and Prices: Foundations of a Theory of Monetary Policy. Princeton: Princeton University Press.

\section{A Technical Appendix}

\section{A.1 Derivation of the Central Bank Welfare Function around a Distorted Steady State}

We know that (see for example Galì 2008 chp. 4) if the steady state is efficient labor market equilibrium implies

$$
C^{\sigma} N^{\phi}=A=\frac{Y}{N}
$$

We now check whether the steady state of our model is efficient or not.

In our model labor supply in steady state is:

$$
C^{\sigma} N^{\phi}=\frac{W}{P} \eta
$$

which comes from the fact that in SS $\tau=1-\eta$. Firms' labor demand in steady state is:

$$
\frac{W}{P}=M C \frac{Y}{N}=\frac{\varepsilon-1}{\varepsilon} \frac{Y}{N}
$$

then, by equating (60) and (61) we get steady state labor market equilibrium is

$$
C^{\sigma} N^{\phi}=M C \eta \frac{Y}{N}=\frac{\varepsilon-1}{\varepsilon} \eta \frac{Y}{N} .
$$

In order to derive the second order approximation of the Central Bank welfare function it is useful to rewrite the previous equation as follows:

$$
\frac{V_{N}(N)}{U_{C}(C)}=M C \eta \frac{Y}{N}
$$


This means that (63) can be rewritten as:

$$
\begin{aligned}
\frac{V_{N}(N)}{U_{C}(C)} & =M C \eta \frac{Y}{N}=\frac{\eta(\varepsilon-1)}{\varepsilon} \\
& =1+\frac{\eta(\varepsilon-1)}{\varepsilon}-1=1-\frac{\varepsilon-\eta(\varepsilon-1)}{\varepsilon} \\
& =1-\Phi
\end{aligned}
$$

where $\Phi<1$ is the steady state distortion, i.e., the steady-state wedge between the marginal rate of substitution between consumption and leisure and the marginal product of labor, and hence the inefficiency of the steady-state output level. Remember in Benigno and Woodford (2005) the steady state distortion is

$$
\Phi=1-\frac{\varepsilon-1}{\varepsilon}(1-\tau)
$$

in our model $\eta$ correspond to $(1-\tau)$ of Benigno and Woodford (2005).

This means that:

$$
V(N) N=U_{C}(C) Y(1-\Phi)
$$

Given that the utility function is separable in consumption and leisure we approximate the two parts of the utility function separately. Consider first the utility of consumption $U\left(C_{t}\right)=U\left(Y_{t}-G_{t}\right)$ which can be approximated up to a second order as:

$$
\begin{aligned}
& U\left(Y_{t}-G_{t}\right) \approx U(Y-G)+U_{C} \frac{d C}{d Y}\left(Y_{t}-Y\right)+\frac{1}{2} U_{C C} \frac{d C}{d Y}\left(Y_{t}-Y\right)^{2}+ \\
& +U_{g y} \frac{d C}{d Y d G} G Y\left(Y_{t}-Y\right)\left(G_{t}-G\right)+U_{C} \frac{d C}{d G}\left(G_{t}-G\right)+\frac{1}{2} U_{C C} \frac{d C}{d G}\left(G_{t}-G\right)^{2}+O\left(\alpha^{3}\right) \\
& \quad \text { where } \frac{d C}{d Y}=1=-\frac{d C}{d G} \text {. Up to a second order } Y_{t}-Y=Y \hat{y}_{t}+\frac{1}{2} Y \hat{y}_{t}^{2} \\
& \text { and }\left(Y_{t}-Y\right)^{2}=Y^{2} \hat{y}_{t}^{2}+O\left(\alpha^{3}\right) \text {. Analogously, } G_{t}-G=G \hat{g}_{t}+\frac{1}{2} G \hat{g}_{t}^{2} \text { and } \\
& \left(G_{t}-G\right)^{2}=G^{2} \hat{g}_{t}^{2}+O\left(\alpha^{3}\right) \text {. Then, considering that } \frac{U_{C C} C}{U_{C}}=-\sigma, \text { the previous } \\
& \text { equation becomes: }
\end{aligned}
$$

$$
\begin{aligned}
U\left(Y_{t}-G_{t}\right) \approx & U(Y-G)+U_{C} Y\left(\hat{y}_{t}+\frac{1}{2} \hat{y}_{t}^{2}-\frac{1}{2} \frac{\sigma}{\gamma_{c}} \hat{y}_{t}^{2}-\frac{\sigma\left(1-\gamma_{c}\right)}{\gamma_{c}} \hat{g}_{t} \hat{y}_{t}\right) \\
& +U_{C} G\left(\hat{g}_{t}+\frac{1}{2} \hat{g}_{t}^{2}-\frac{1}{2} \frac{\sigma\left(1-\gamma_{c}\right)^{2}}{\gamma_{c}} \hat{g}_{t}^{2}\right)+O\left(\alpha^{3}\right) .
\end{aligned}
$$

Collecting terms and recalling that $U\left(Y_{t}-G_{t}\right)-U(Y-G)=\tilde{U}\left(Y_{t}-G_{t}\right)$ :

$$
\tilde{U}\left(Y_{t}-G_{t}\right) \approx U_{C} Y\left(\begin{array}{c}
\hat{y}_{t}+\frac{1}{2} \hat{y}_{t}^{2}-\frac{\sigma}{\gamma_{c}} \hat{y}_{t}^{2}-\frac{\sigma\left(1-\gamma_{c}\right)}{\gamma_{c}} \hat{g}_{t} \hat{y}_{t} \\
+\hat{g}_{t}+\frac{1}{2} \hat{g}_{t}^{2}-\frac{1}{2} \frac{\sigma\left(1-\gamma_{c}\right)^{2}}{\gamma_{c}} \hat{g}_{t}^{2}
\end{array}\right)+O\left(\alpha^{3}\right)
$$


Now consider the second order approximation of the utility of leisure $V\left(N_{t}\right)$, after collecting terms and given that $\frac{V_{N N} N}{V_{N}}=\phi$ and that $V\left(N_{t}\right)-V_{N} N=$ $\tilde{V}\left(N_{t}\right)$ we get:

$$
\tilde{V}\left(N_{t}\right) \approx V_{N} N\left(\hat{n}_{t}+\frac{1}{2} \hat{n}_{t}+\frac{\phi}{2} \hat{n}_{t}^{2}\right)+O\left(\alpha^{3}\right)
$$

subtracting (67) from (66) we get:

$$
\begin{aligned}
\tilde{W}_{t}= & U_{C} Y\left(\begin{array}{c}
\hat{y}_{t}+\frac{1}{2} \hat{y}_{t}^{2}-\frac{\sigma}{\gamma_{c}} \hat{y}_{t}^{2}-\frac{\sigma\left(1-\gamma_{c}\right)}{\gamma_{c}} \hat{g}_{t} \hat{y}_{t} \\
+\hat{g}_{t}+\frac{1}{2} \hat{g}_{t}^{2}-\frac{1}{2} \frac{\sigma\left(1-\gamma_{c}\right)^{2}}{\gamma_{c}} \hat{g}_{t}^{2}
\end{array}\right)+ \\
& -V_{N} N\left(\hat{n}_{t}+\frac{1}{2} \hat{n}_{t}+\frac{\phi}{2} \hat{n}_{t}^{2}\right)+O\left(\alpha^{3}\right) .
\end{aligned}
$$

We know that in the steady state $V(N) N=U_{C}(C) Y(1-\Phi)$, therefore we can rewrite (68) as follows:

$$
\begin{aligned}
\tilde{W}_{t}= & U_{C} Y\left(\begin{array}{c}
\hat{y}_{t}+\frac{1}{2} \hat{y}_{t}^{2}-\frac{\sigma}{\gamma_{c}} \hat{y}_{t}^{2}-\frac{\sigma\left(1-\gamma_{c}\right)}{\gamma_{c}} \hat{g}_{t} \hat{y}_{t} \\
+\hat{g}_{t}+\frac{1}{2} \hat{g}_{t}^{2}-\frac{1}{2} \frac{\sigma\left(1-\gamma_{c}\right)^{2}}{\gamma_{c}} \hat{g}_{t}^{2}
\end{array}\right)+ \\
& -U_{C}(C) Y(1-\Phi)\left(\hat{n}_{t}+\frac{1+\phi}{2} \hat{n}_{t}^{2}\right)+O\left(\alpha^{3}\right) .
\end{aligned}
$$

From the production function we know that $\hat{n}_{t}=\hat{y}_{t}-a_{t}+d_{t}$ and $\hat{n}_{t}^{2}=$ $\left(\hat{y}_{t}-a_{t}\right)^{2}$ and collecting terms:

$\tilde{W}_{t}=U_{C} Y\left[\begin{array}{c}\Phi \hat{y}_{t}+\frac{1}{2}\left(\frac{1-\sigma}{\gamma_{c}}-(1-\Phi)(1+\phi)\right) \hat{y}_{t}^{2}-(1-\Phi) d_{t} \\ +\frac{\sigma\left(1-\gamma_{c}\right)}{\gamma_{c}} \hat{g}_{t} \hat{y}_{t}+(1-\Phi)(1+\phi) \hat{y}_{t} a_{t}\end{array}\right]+$ t.i.p. $+O\left(\alpha^{3}\right)$.

Given lemma 1 and lemma 2 in Woodford (2003 chp. 6) we know that $d_{t}=\frac{\varepsilon}{2} \operatorname{var}_{i}\left\{p_{i, t}\right\}$ and $\sum_{t=0}^{\infty} \beta^{t} \operatorname{var}_{i}\left\{p_{i, t}\right\}=\sum_{t=0}^{\infty} \beta^{t} \lambda^{-1} \operatorname{var}_{i}\left\{p_{i, t}\right\}$. Using these two results we finally get the following intertemporal Welfare Based Loss function:

$W_{0}=-\frac{1}{2} U_{c} Y E_{0} \sum_{t=0}^{\infty} \beta^{t}\left[\begin{array}{c}-\Phi \hat{y}_{t}+\frac{\gamma_{c}(1-\Phi)(1+\phi)-(1-\sigma)}{\gamma_{c}} \hat{y}_{t}^{2} \\ -\frac{\sigma\left(1-\gamma_{c}\right)}{\gamma_{c}} \hat{g}_{t} \hat{y}_{t}-(1-\Phi)(1+\phi) \hat{y}_{t} a_{t}+(1-\Phi) \frac{\varepsilon}{\lambda} \pi_{t}^{2}\end{array}\right]+$ t.i.p.

Notice that (71) when $\Phi>0$ there is a non-zero linear term in (71) which means that we cannot evaluate this equation to second order using a loglinear approximation for the path of aggregate output. Thus we cannot study optimal policy using the log-linear approximation of the competitive 
equilibrium economy. Rotemberg and Woodford (1997) avoid this problem by introducing subsidies to ensure that $\Phi=0$. We relax this assumption and in solving the optimal problem we follow Benigno and Woodford (2005) who show that the first order term in equation (71) can be eliminated by taking a second-order approximation of the aggregate supply relation, that is by taking the second order approximation of the following equation:

$$
\left\{\begin{array}{l}
\frac{1-\varphi \Pi_{t}^{\varepsilon-1}}{1-\varphi}=\left(\frac{K_{t}}{F_{t}}\right)^{1-\varepsilon} \\
K_{t}=M C_{t} Y_{t}+\varphi \beta E_{t}\left\{\Pi_{t+1}^{\varepsilon} K_{t+1}\right\} \\
F_{t}=Y_{t}+\varphi \beta E_{t}\left\{\Pi_{t+1}^{\varepsilon-1} F_{t+1}\right\}
\end{array}\right.
$$

where (72) is the standard first order condition we get when solving the Calvo price-setting problem. A second order approximation of the aggregate supply (72) yields

$$
V_{0}=\lambda \frac{1}{2} E_{0} \sum_{t=0}^{\infty} \beta^{t}\left[\begin{array}{c}
\mu_{y} \hat{y}_{t}+\mu_{y}^{2} \hat{y}_{t}^{2}+\left(1+\mu_{\pi}\right) \frac{\varepsilon}{\lambda} \pi_{t}^{2}+ \\
-\mu_{y}\left(\frac{1+\phi}{1-\phi_{n}}\right) \hat{y}_{t} a_{t}-\mu_{y}\left(\frac{\sigma\left(1-\gamma_{c}\right)}{\gamma_{c}\left(1-\phi_{n}\right)}\right) \hat{y}_{t} g_{t}
\end{array}\right]+\text { t.i.p. }
$$

where $\lambda=\frac{(1-\varphi)(1-\varphi \beta)}{\varphi}, \mu_{y}=\frac{\sigma+\gamma_{c}\left(\phi+\phi_{n}\right)}{\left(1-\phi_{n}\right) \gamma_{c}}$, and $\mu_{\pi}=\frac{\phi+\phi_{n}}{\left(1-\phi_{n}\right)}$. Subtracting $\mu_{y}^{-1} U_{c} Y \frac{\Phi}{\lambda} V_{0}$ from $W_{0}$ we get

$$
W_{0}^{\prime}=-\frac{1}{2} U_{c} Y E_{0} \sum_{t=0}^{\infty} \beta^{t}\left[q_{x} \hat{y}_{t}^{2}+q_{\pi} \pi_{t}^{2}-q_{g} \hat{g}_{t} \hat{y}_{t}-q_{a} \hat{y}_{t} a_{t}\right]+\text { t.i.p. }
$$

where $q_{x}=\left(\frac{\gamma_{c}(1-\Phi)(1+\phi)-(1-\sigma)}{\gamma_{c}}+\mu_{y} \Phi\right), q_{\pi}=\left((1-\Phi)+\frac{\left(1+\mu_{\pi}\right) \Phi}{\mu_{y}}\right) \frac{\varepsilon}{\lambda}, q_{a}=$ $(1-\Phi)(1+\phi)+\left(\frac{1+\phi}{1-\phi_{n}}\right) \Phi$ and $q_{g}=\frac{\sigma\left(1-\gamma_{c}\right)}{\gamma_{c}}+\left(\frac{\sigma\left(1-\gamma_{c}\right)}{\gamma_{c}\left(1-\phi_{n}\right)}\right) \Phi$.

To simplify the analysis we now consider the case in which $\sigma=1$ and $\gamma_{c}=1$. The coefficient of equation (74) becomes

$$
\left\{\begin{array}{l}
q_{x}=\left((1-\Phi)(1+\phi)+\frac{1+\phi+\phi_{n}}{1-\phi_{n}} \Phi\right) \\
q_{\pi}=\left((1-\Phi)+\frac{1+\phi}{1+\phi+\phi_{n}} \Phi\right) \frac{\varepsilon}{\lambda}=\frac{1+\phi+\Phi \phi_{n}}{1+\phi+\phi_{n}} \frac{\varepsilon}{\lambda} \\
q_{a}=(1-\Phi)(1+\phi)+\left(\frac{1+\phi}{1-\phi_{n}}\right) \Phi
\end{array}\right.
$$

which are the coefficient of the welfare-loss (43) in the main text. From (74) it is now easy to define the welfare relevant output gap as a weighted average of natural and efficient equilibrium output:

$$
\hat{y}_{t}^{*}=q_{x}^{-1}\left((1+\phi)(1-\Phi) \hat{y}_{t}^{E f f}+\left(\frac{1+\phi+\phi_{n}}{1-\phi_{n}}\right) \Phi \hat{y}_{t}^{n}\right)
$$


where $\hat{y}_{t}^{E f f}=a_{t}$ and $\hat{y}_{t}^{n}=\frac{1+\phi}{1+\phi+\phi_{n}} a_{t}$, so that $\hat{y}_{t}^{*}$ can be rewritten in terms of the shock.

$$
\hat{y}_{t}^{*}=(1+\phi)(1-\Phi) a_{t}+\left(\frac{1+\phi}{1-\phi_{n}}\right) \Phi a_{t}
$$

Notice that the weights in (76) depends on the steady state distortion $\Phi$. The welfare-loss can be now rewritten in terms of output gap from the welfare relevant output as in the main text (equation (43)).

The NKPC is

$$
\pi_{t}=\beta E_{t} \pi_{t+1}+\kappa\left(\hat{y}_{t}-\hat{y}_{t}^{n}\right)
$$

where $\kappa=\lambda \frac{1+\phi+\phi_{n}}{1-\phi_{n}}$. Adding and subtracting $\hat{y}_{t}^{*}$

$$
\pi_{t}=\beta E_{t} \pi_{t+1}+\kappa\left(y_{t}-\hat{y}_{t}^{*}\right)+\kappa\left(\hat{y}_{t}^{*}-\hat{y}_{t}^{n}\right)
$$

In the main text we call $u_{t}=\left(\hat{y}_{t}^{*}-\hat{y}_{t}^{n}\right)$.

Notice that given the definition of $q_{x}$, then $\hat{y}_{t}^{*}$ can be written as:

$$
\hat{y}_{t}^{*}=\alpha_{1} \hat{y}_{t}^{E f f}+\left(1-\alpha_{1}\right) \hat{y}_{t}^{n}
$$

where $\alpha_{1}=\frac{(1+\phi)(1-\Phi)}{q_{x}}$ so that $\frac{\left(\frac{1+\phi+\phi_{n}}{1-\phi_{n}}\right) \Phi}{q_{x}}=1-\alpha_{1}$ and (79) can be rewritten as,

$$
\pi_{t}=\beta E_{t} \pi_{t+1}+\lambda \frac{1+\phi+\phi_{n}}{1-\phi_{n}}\left(y_{t}-\hat{y}_{t}^{*}\right)+\kappa \alpha_{1}\left(\hat{y}_{t}^{E f f}-\hat{y}_{t}^{n}\right)
$$

or

$$
\pi_{t}=\beta E_{t} \pi_{t+1}+\lambda \frac{1+\phi+\phi_{n}}{1-\phi_{n}}\left(y_{t}-\hat{y}_{t}^{*}\right)+\lambda \frac{(1+\phi)(1-\Phi) \phi_{n}}{\left(1-\phi_{n}\right) q_{x}} a_{t}
$$

We can finally rewrite the NKPC used to study optimal monetary policy, both under discretion and commitment, as

$$
\pi_{t}=\beta E_{t} \pi_{t+1}+\kappa\left(y_{t}-\hat{y}_{t}^{*}\right)+\zeta_{a} a_{t}
$$

where $\zeta_{a}=\lambda \frac{(1+\phi)(1-\Phi) \phi_{n}}{\left(1-\phi_{n}\right) q_{x}}$

Finally, notice that for $\phi_{n}=0$, then we get the same equation as Benigno and Woodford (2005) and Gnocchi (2009) among others. Indeed,

$$
\begin{aligned}
& q_{x}=(1+\phi) \\
& q_{\pi}=\frac{\varepsilon}{\lambda} \\
& q_{a}=(1+\phi)
\end{aligned}
$$


and the welfare loss becomes

$$
W_{0}^{\prime}=-\frac{1}{2} U_{c} Y E_{0} \sum_{t=0}^{\infty} \beta^{t}\left[\pi_{t}^{2}+\frac{\lambda}{\varepsilon}(1+\phi) x_{t}^{2}\right]+\text { t.i.p. }
$$

Notice also that in the case in which $\phi_{n}=0$, the coefficient $\zeta_{a}=0$ and the NKPC (83) becomes

$$
\pi_{t}=\beta E_{t} \pi_{t+1}+\kappa\left(y_{t}-\hat{y}_{t}^{*}\right)
$$

This means that the monetary authority does not face any trade-off in stabilizing inflation and output gap. Therefore, when $\pi_{t}=0$, the output gap becomes also equal to zero and the welfare-loss is nil.

\section{A.2 Proof of Preposition 5}

We want to prove that the sign of the derivative of the inflation coefficient of the optimal interest rate rule (46), i.e. $1+\frac{\kappa \sigma(1-\rho)}{a_{x} \rho}$ with respect to $\phi_{n}$ is greater than zero.

Notice that after some algebra we can rewrite the coefficient as:

$$
1+\frac{\kappa \sigma(1-\rho)}{a_{x} \rho}=1+\frac{\left(1+\phi+\Phi \phi_{n}\right) \varepsilon}{\left((1+\phi)\left(\left(1-\phi_{n}\right)+\phi_{n} \Phi\right)+\phi_{n} \Phi\right)} \frac{\sigma(1-\rho)}{\rho}
$$

It is sufficient to study the sign of the derivative $\frac{\kappa}{\alpha_{x}}=\frac{\left(1+\phi+\Phi \phi_{n}\right) \varepsilon}{\left((1+\phi)\left(\left(1-\phi_{n}\right)+\phi_{n} \Phi\right)+\phi_{n} \Phi\right)}$ with respect to $\phi_{n}$, which is

$$
\frac{d\left(\frac{\kappa}{\alpha_{x}}\right)}{d \phi_{n}}=-\varepsilon(\Phi-1) \frac{(\phi+1)^{2}}{\left(\phi-\phi_{n}+2 \phi_{n} \Phi-\phi_{n} \phi+\phi_{n} \Phi \phi+1\right)^{2}}
$$

Remember that $\Phi<1$, then it holds that:

$$
\frac{d\left(\frac{\kappa}{\alpha_{x}}\right)}{d \phi_{n}}>0
$$




\section{A.3 Determinacy under rule (48)}

The reduced form for the optimal rule (48) is:

$$
\begin{aligned}
\left(\begin{array}{c}
\pi_{t} \\
x_{t}
\end{array}\right)= & \underbrace{\left[\begin{array}{cc}
\beta \alpha_{x}\left(\alpha_{x}+\kappa^{2}\right)^{-1} & 0 \\
-\beta \kappa\left(\alpha_{x}+\kappa^{2}\right)^{-1} & 0
\end{array}\right]}_{A} E_{t}\left(\begin{array}{c}
\pi_{t+1} \\
x_{t+1}
\end{array}\right) \\
& + \text { t.n.a.d. }
\end{aligned}
$$

where t.n.a.d. states for terms not affecting determinacy of the REE. The optimal rule is always determinate if the roots of the characteristics equation $\operatorname{det}(C)=\operatorname{det}[A-\mu I]$ lie inside the unit circle. Notice that

$$
\operatorname{det}(C)=\operatorname{det}\left[\begin{array}{cc}
\beta \alpha_{x}\left(\alpha_{x}+\kappa^{2}\right)^{-1}-\mu & 0 \\
-\beta \kappa\left(\alpha_{x}+\kappa^{2}\right)^{-1} & \mu
\end{array}\right]=\mu\left(\beta \alpha_{x}\left(\alpha_{x}+\kappa^{2}\right)^{-1}-\mu\right)
$$

which has the following solutions: $\mu_{1}=0$ and $\mu_{2}=\frac{\beta \alpha_{x}}{\left(\alpha_{x}+\kappa^{2}\right)}<1$. Thus, both roots lie inside the unite circle and the optimal rule (48) is always determinate. 


\begin{tabular}{|c|c|c|c|c|}
\hline \multirow[b]{2}{*}{ Country } & \multicolumn{4}{|c|}{$\%$ AW } \\
\hline & $67 \%$ & $100 \%$ & $133 \%$ & $167 \%$ \\
\hline Australia & $35,5 \%$ & $31,5 \%$ & $41,5 \%$ & $41,5 \%$ \\
\hline Austria & $26,8 \%$ & $30,4 \%$ & $30,4 \%$ & $37,5 \%$ \\
\hline Belgium & $40,8 \%$ & $40,8 \%$ & $45,3 \%$ & $46,7 \%$ \\
\hline Canada & $19,6 \%$ & $30,1 \%$ & $31,1 \%$ & $33,0 \%$ \\
\hline Czech Republic & $20,2 \%$ & $20,3 \%$ & $20,2 \%$ & $20,3 \%$ \\
\hline Denmark & $34,6 \%$ & $41,4 \%$ & $55,0 \%$ & $55,0 \%$ \\
\hline Finland & $36,5 \%$ & $41,6 \%$ & $41,6 \%$ & $41,6 \%$ \\
\hline France & $18,0 \%$ & $18,0 \%$ & $30,1 \%$ & $30,1 \%$ \\
\hline Germany & $30,6 \%$ & $37,3 \%$ & $42,9 \%$ & $44,3 \%$ \\
\hline Greece & $22,7 \%$ & $22,7 \%$ & $22,7 \%$ & $31,1 \%$ \\
\hline Hungary & $27,0 \%$ & $45,0 \%$ & $36,0 \%$ & $36,0 \%$ \\
\hline Iceland & $34,3 \%$ & $34,3 \%$ & $34,3 \%$ & $34,3 \%$ \\
\hline Ireland & $20,0 \%$ & $20,0 \%$ & $41,0 \%$ & $41,0 \%$ \\
\hline Italy & $29,2 \%$ & $29,2 \%$ & $39,1 \%$ & $38,7 \%$ \\
\hline Japan & $8,7 \%$ & $13,6 \%$ & $23,3 \%$ & $25,6 \%$ \\
\hline Luxembourg & $21,9 \%$ & $34,7 \%$ & $34,7 \%$ & $34,7 \%$ \\
\hline Mexico & $10,8 \%$ & $10,8 \%$ & $17,8 \%$ & $19,9 \%$ \\
\hline Netherlands & $11,1 \%$ & $40,5 \%$ & $52,0 \%$ & $52,0 \%$ \\
\hline New Zealand & $21,0 \%$ & $33,0 \%$ & $36,0 \%$ & $39,0 \%$ \\
\hline Norway & $28,0 \%$ & $37,0 \%$ & $37,0 \%$ & $40,0 \%$ \\
\hline Poland & $9,7 \%$ & $9,7 \%$ & $9,7 \%$ & $19,2 \%$ \\
\hline Portugal & $23,5 \%$ & $23,5 \%$ & $34,0 \%$ & $34,0 \%$ \\
\hline Slovak Republic & $16,5 \%$ & $16,5 \%$ & $16,7 \%$ & $16,7 \%$ \\
\hline Spain & $22,5 \%$ & $26,2 \%$ & $26,2 \%$ & $37,0 \%$ \\
\hline Sweden & $23,4 \%$ & $44,4 \%$ & $51,4 \%$ & $56,4 \%$ \\
\hline Switzerland & $16,0 \%$ & $17,7 \%$ & $22,7 \%$ & $26,8 \%$ \\
\hline Turkey & $17,6 \%$ & $17,6 \%$ & $23,5 \%$ & $23,5 \%$ \\
\hline United Kingdom & $20,0 \%$ & $20,0 \%$ & $40,0 \%$ & $40,0 \%$ \\
\hline United States & $21,7 \%$ & $21,7 \%$ & $31,7 \%$ & $31,7 \%$ \\
\hline
\end{tabular}

Table 1. Marginal Personal Income Tax Rate, (year: 2008). Source: OECD 


\begin{tabular}{|c|c|c|c|c|c|c|}
\hline Country & Elasticities & Av. tax rates & $\Phi_{n}$ & St.d. Y & St.d. H & St.d. T \\
\hline Australia & 1.5 & 0,24 & 0,16 & 0,68 & 0,52 & 0,59 \\
\hline Austria & 2,2 & 0,12 & 0,16 & 1,49 & 0,39 & 0,37 \\
\hline Belgium & 1,6 & 0,28 & 0,23 & 1,22 & 0,78 & 0,50 \\
\hline Canada & 1,6 & 0,17 & 0,12 & 1,11 & 0,44 & 0,65 \\
\hline Czek Republic & 1,7 & 0,11 & 0,09 & 2,14 & 1,49 & 0,88 \\
\hline Denmark & 1,4 & 0,41 & 0,28 & 1,68 & 0,36 & 0,47 \\
\hline Finland & 1,5 & 0,25 & 0,17 & 2,41 & 0,50 & 0,42 \\
\hline France & 1,7 & 0,29 & 0,29 & 1,09 & 1,31 & 0,40 \\
\hline Germany & 2,3 & 0,22 & 0,37 & 1,66 & 0,62 & 0,33 \\
\hline Greece & 2 & 0,23 & 0,30 & 1,50 & 0,86 & 1,35 \\
\hline Hungary & 2,4 & 0,22 & 0,39 & 1,60 & 0,65 & 0,89 \\
\hline Ireland & 2,1 & 0,17 & 0,23 & 2,82 & 0,53 & 0,79 \\
\hline Italy & 2 & 0,29 & 0,41 & 1,42 & 0,44 & 0,29 \\
\hline Japan & 2 & 0,19 & 0,23 & 1,68 & 0,55 & 0,42 \\
\hline Netherlands & 2,4 & 0,32 & 0,66 & 1,59 & 0,73 & 0,49 \\
\hline New Zeland & 1,3 & 0,2 & 0,08 & 1,04 & 1,03 & 0,46 \\
\hline Norway & 1,5 & 0,22 & 0,14 & 0,98 & 0,68 & 0,78 \\
\hline Portugal & 1,7 & 0,22 & 0,20 & 1,21 & 0,79 & 0,63 \\
\hline Slovakia & 1 & 0,08 & 0,00 & 2,76 & 2,05 & 1,47 \\
\hline Spain & 2,1 & 0,2 & 0,28 & 1,43 & 0,58 & 0,92 \\
\hline Sweden & 1,3 & 0,3 & 0,13 & 1,85 & 1,14 & 0,61 \\
\hline Switzerland & 1,8 & 0,11 & 0,10 & 1,34 & 1,04 & 0,66 \\
\hline United Kingdom & 1,7 & 0,26 & 0,25 & 1,40 & 0,45 & 0,53 \\
\hline United States & 1,9 & 0,17 & 0,18 & 1,23 & 0,47 & 0,77 \\
\hline
\end{tabular}

Table 2. Earning elasticities (André and Girouard 2005), average income tax, tax progressivity and standard deviations of dependent variables. 

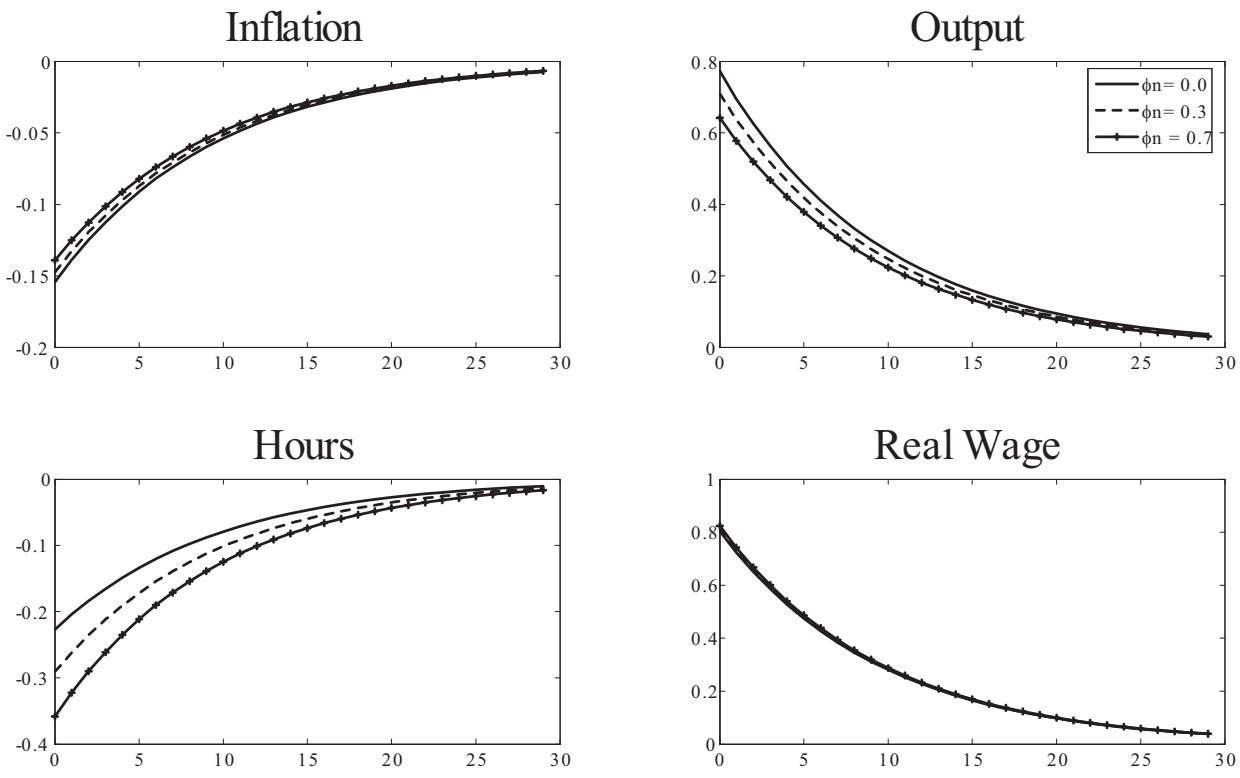

Fig. 1. IRFs to a $1 \%$ technology shock
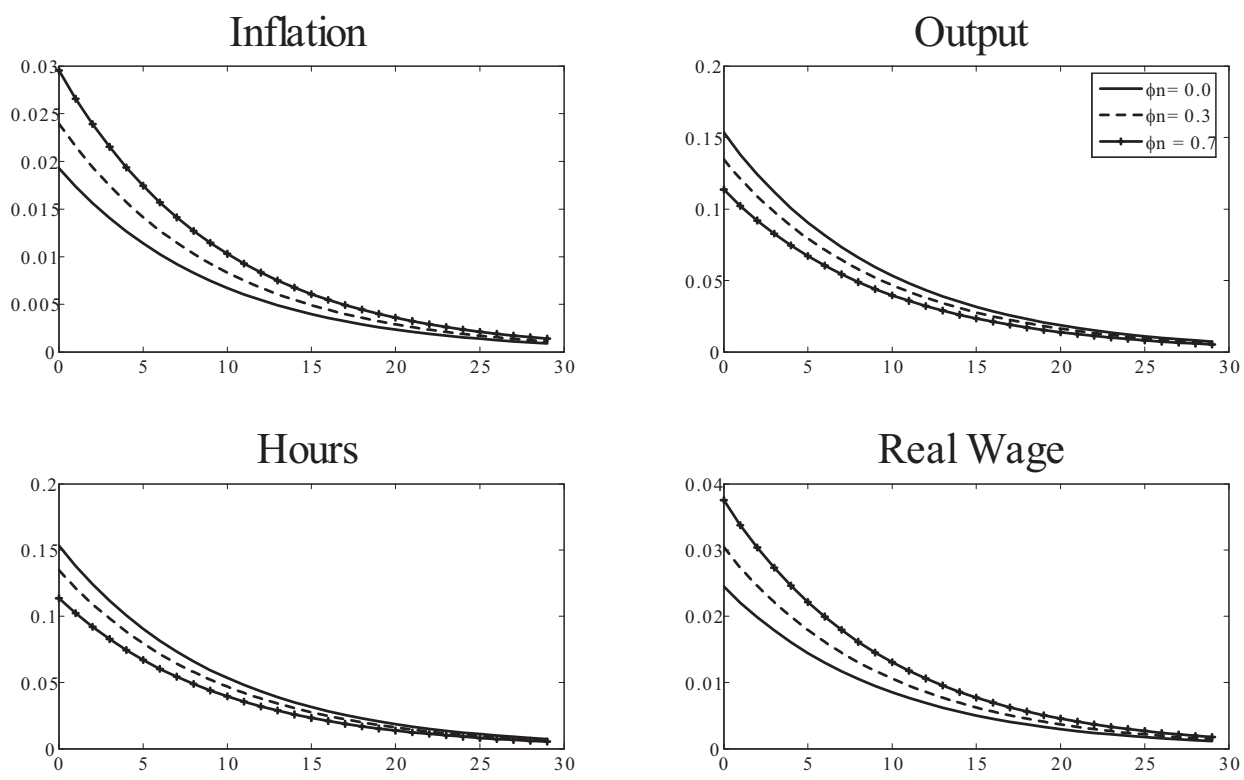

Figure 2. IRFs to a positive 1\% Government Spending shock 

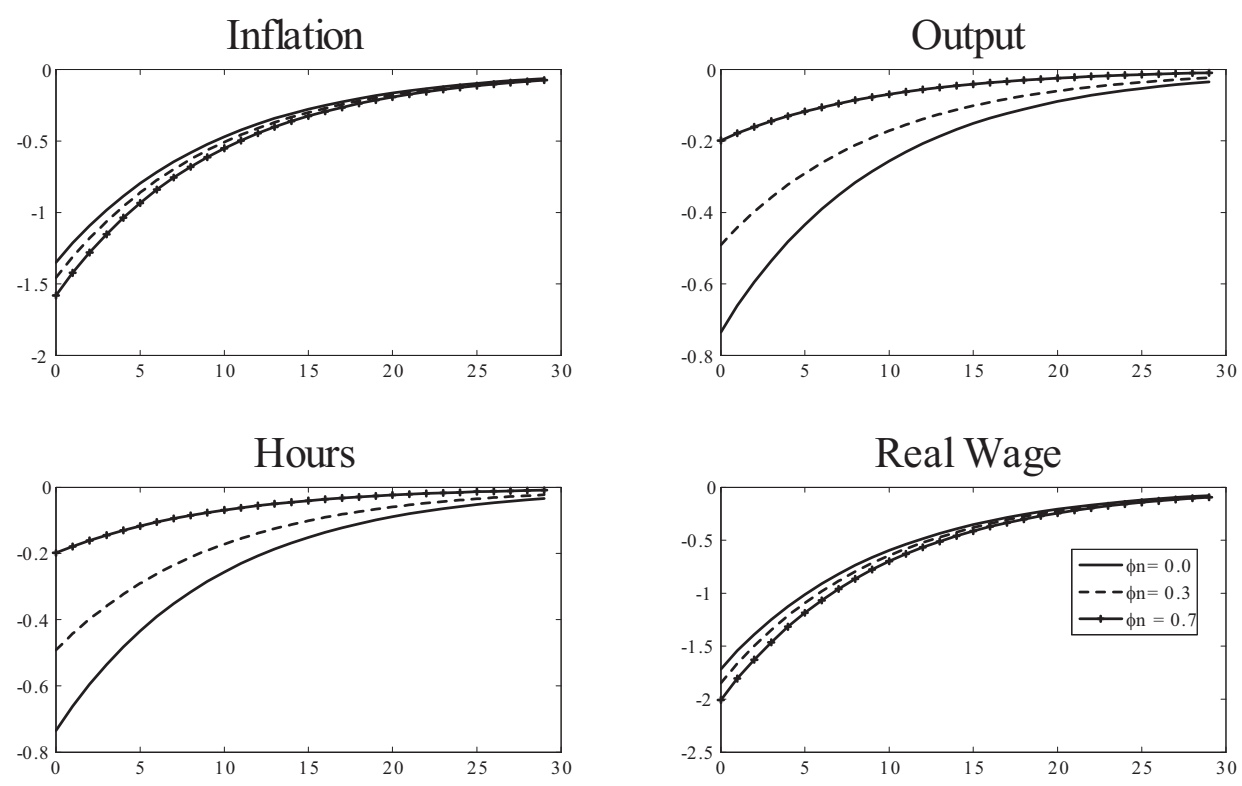

Fig. 3. IRFs to a $1 \%$ monetary shock

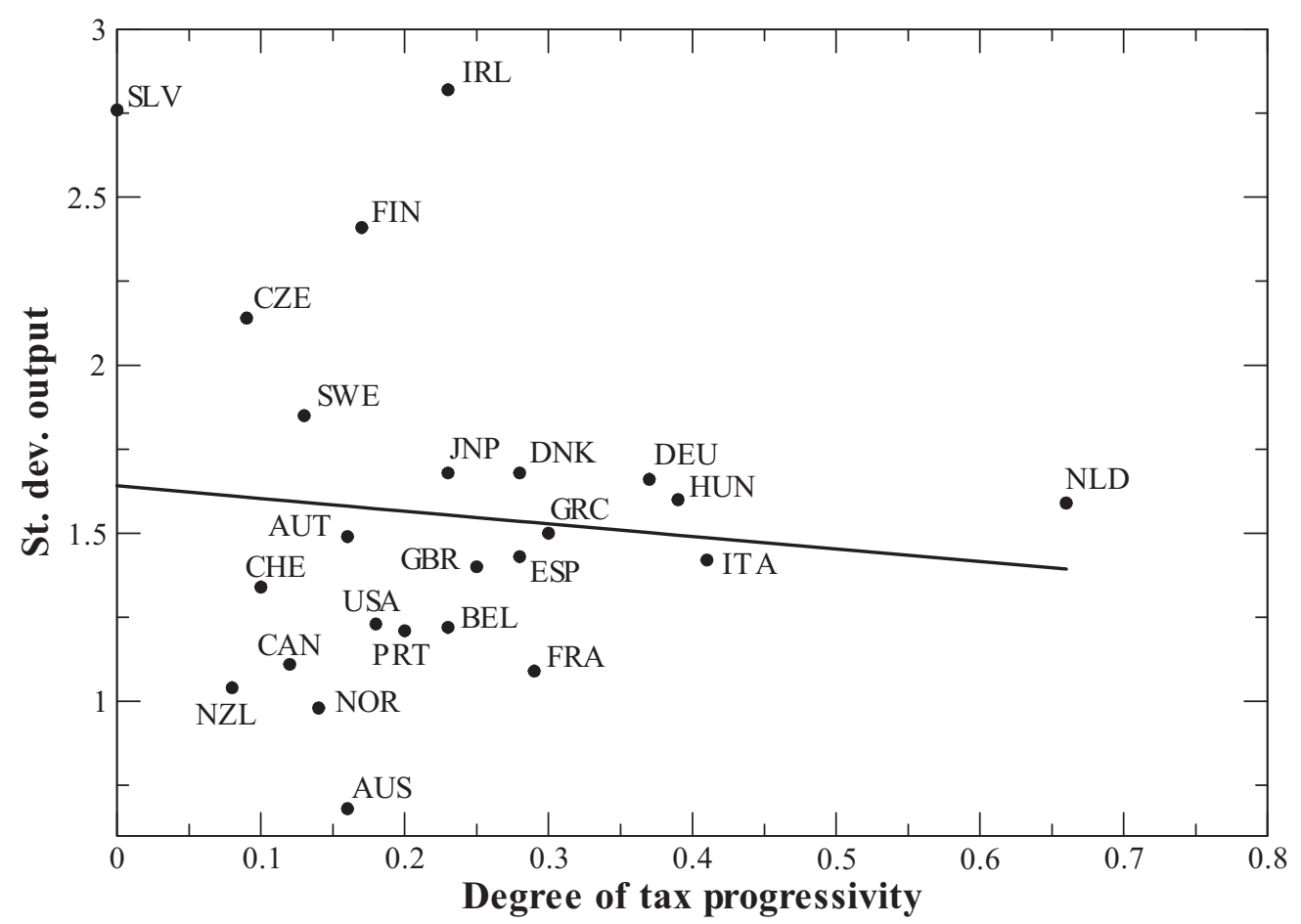

Figure 4. Degree of tax progressivity and volatility of real GDP 


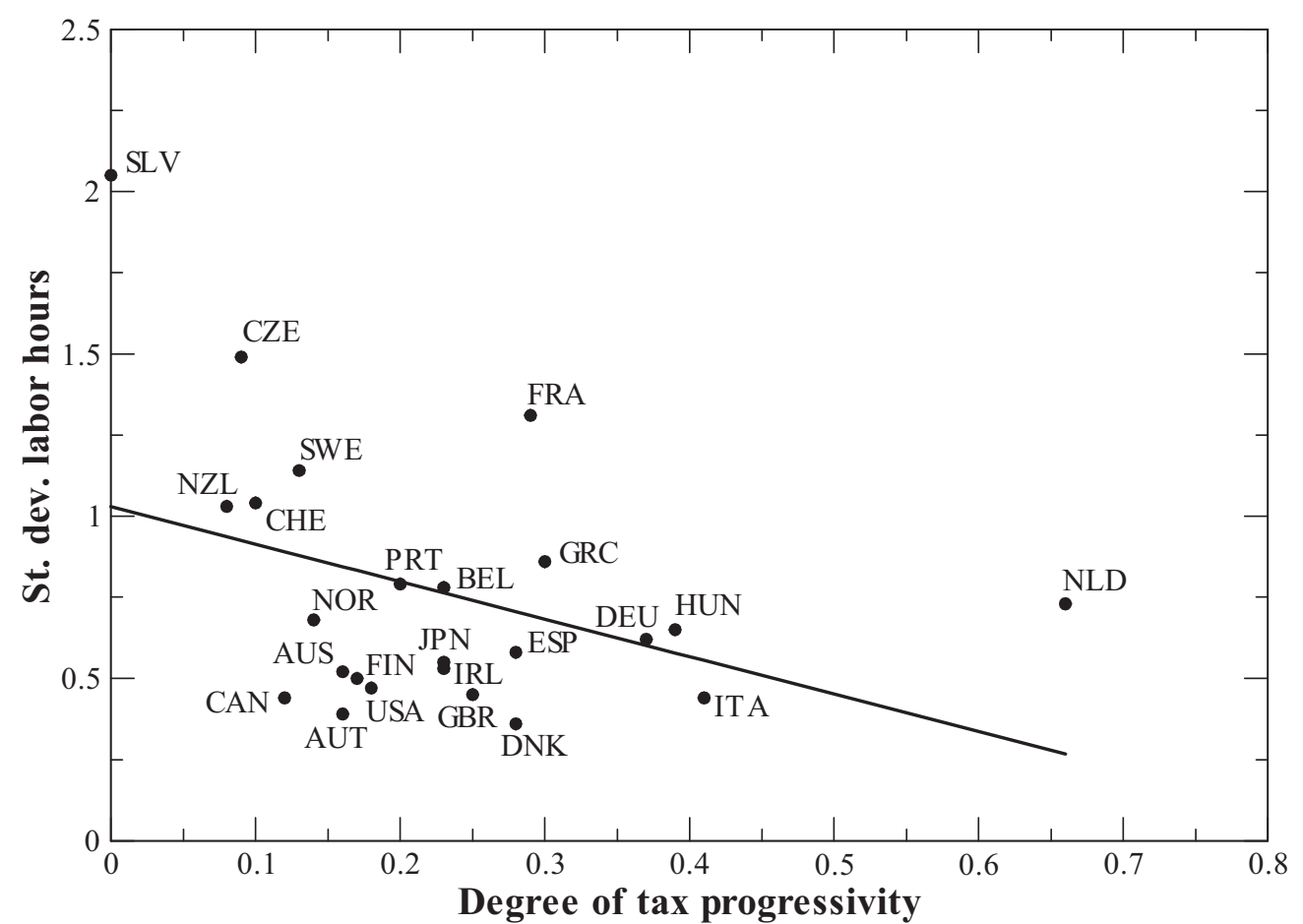

Figure 5. Degree of tax progressivity and volatility of labor hours

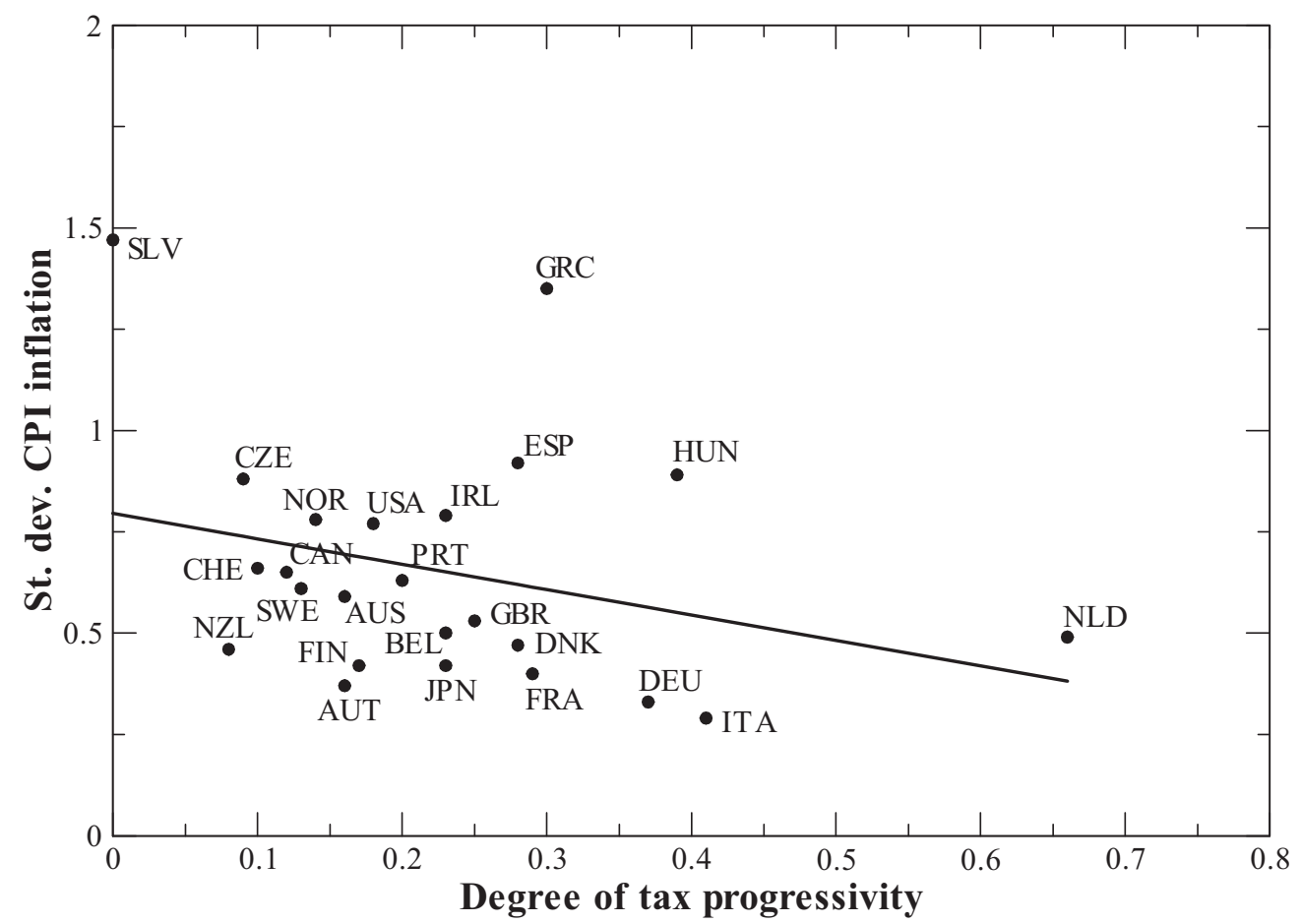

Figure 6. Degree of tax progressivity and volatility of CPI inflation 
Effect on Welfare of Varying $\rho_{a}$ and $\phi_{n}$ on the welfare gains from commitment

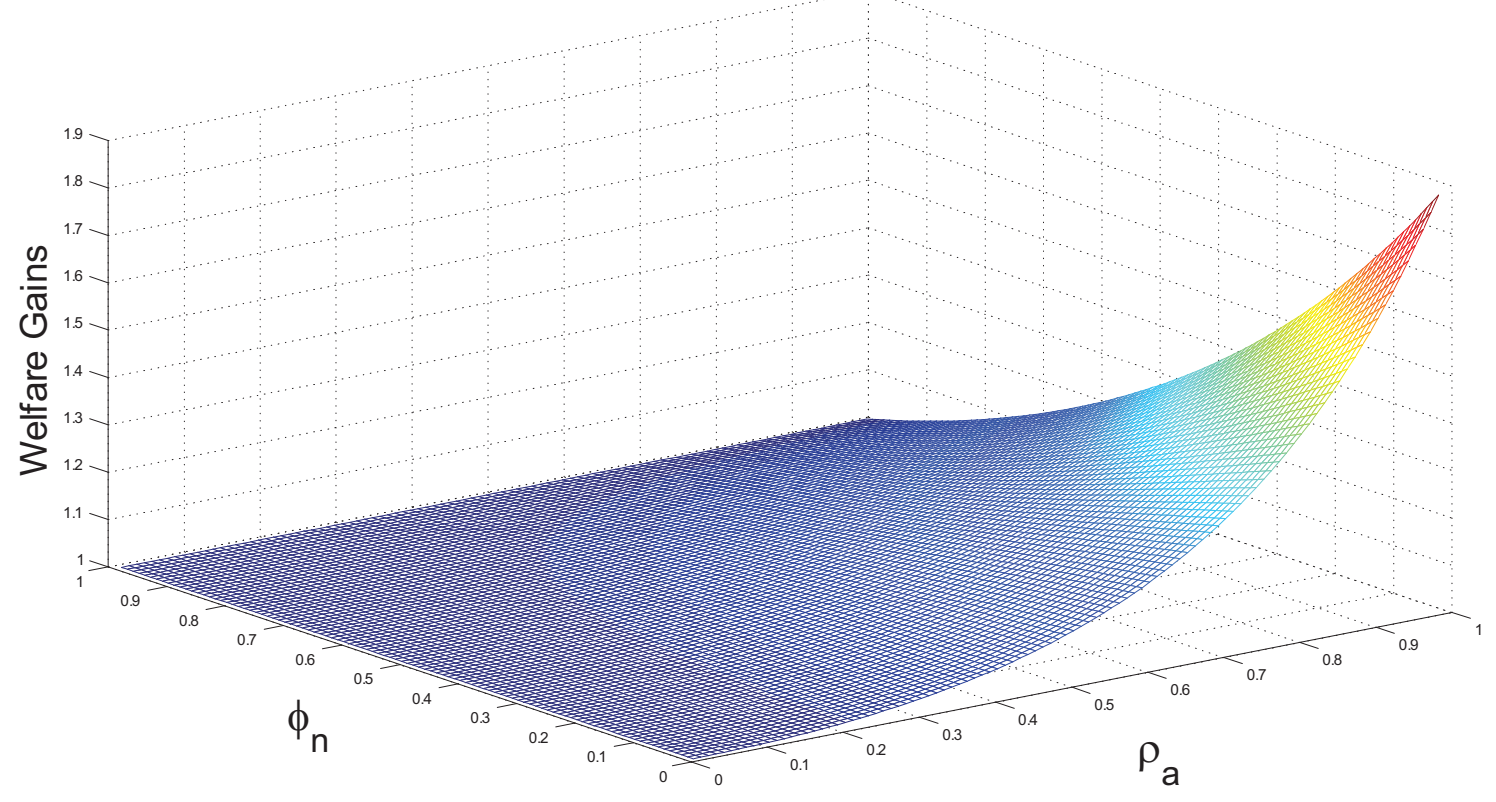

Fig. 7 Welfare Gains from Commitment 